\title{
REVIEW
}

\section{Regulators of the RAS-ERK pathway as therapeutic targets in thyroid cancer}

\author{
Miguel A Zaballos'1,2, Adrián Acuña-Ruiz1,2, Marta Morante2,3, Piero Crespo 2,3 and Pilar Santisteban 1,2 \\ 'Instituto de Investigaciones Biomédicas 'Alberto Sols', Consejo Superior de Investigaciones Científicas (CSIC), Universidad Autónoma de Madrid (UAM), \\ Madrid, Spain \\ ${ }^{2}$ Centro de Investigación Biomédica en Red de Cáncer (CIBERONC), Instituto de Salud Carlos III, Madrid, Spain \\ ${ }^{3}$ Instituto de Biomedicina y Biotecnología de Cantabria (IBBTEC), Consejo Superior de Investigaciones Científicas (CSIC), Universidad de Cantabria, \\ Santander, Spain
}

Correspondence should be addressed to P Santisteban: psantisteban@iib.uam.es

\begin{abstract}
Thyroid cancer is mostly an ERK-driven carcinoma, as up to $70 \%$ of thyroid carcinomas are caused by mutations that activate the RAS/ERK mitogenic signaling pathway. The incidence of thyroid cancer has been steadily increasing for the last four decades; yet, there is still no effective treatment for advanced thyroid carcinomas. Current research efforts are focused on impairing ERK signaling with small-molecule inhibitors, mainly at the level of BRAF and MEK. However, despite initial promising results in animal models, the clinical success of these inhibitors has been limited by the emergence of tumor resistance and relapse. The RAS/ERK pathway is an extremely complex signaling cascade with multiple points of control, offering many potential therapeutic targets: from the modulatory proteins regulating the activation state of RAS proteins to the scaffolding proteins of the pathway that provide spatial specificity to the signals, and finally, the negative feedbacks and phosphatases responsible for inactivating the pathway. The aim of this review is to give an overview of the biology of RAS/ERK regulators in human cancer highlighting relevant information on thyroid cancer and future areas of research.
\end{abstract}
Key Words
- thyroid cancer
- RAS/ERK
- GEF/GAP
- scaffold
- MKP

\section{An overview of thyroid cancer}

Thyroid cancer is the most common of the endocrine malignancies and its incidence has been steadily rising during the last four decades (Lim et al. 2017). Approximately $90 \%$ of all thyroid carcinomas derive from thyroid follicular cells, a monolayer of epithelial cells that renders the follicles and fulfills the main function of the gland - the synthesis and secretion of thyroid hormones (Colin \& Gerard 2010). A second cellular type specific for the thyroid is the parafollicular or C-cell, which is responsible for calcitonin production and gives rise to medullary thyroid carcinoma (MTC). In this review, we will discuss only those carcinomas arising from the follicular cells, since they represent the vast majority of malignant lesions of the thyroid gland. Papillary thyroid carcinoma (PTC) is the most frequent histotype of thyroid tumor, with an incidence of $\sim 80 \%$ (Hay et al. 2002), followed by follicular thyroid carcinoma (FTC), which represents $10-15 \%$ of all tumors. Both carcinomas can be classified as well-differentiated thyroid carcinomas (WDTC), which have a low proliferative index and mutational density and, consequently, a good prognosis. The current treatment for these cancers is removal of the gland (thyroidectomy) followed by radioiodine and thyroid hormone replacement therapy, which has proven a very effective approach with 5- to 10-year survival rates of $90-98 \%$. However, a subset of those WDTC 
progress to very aggressive, albeit rare (1-6\%) variants termed the poorly differentiated (Volante et al. 2007) and anaplastic (Smallridge et al. 2009) thyroid carcinomas (PDTC and ATC, respectively), which are characterized by an extremely high proliferation rate and mutational burden, local and disseminated metastases, and a dismal outcome, with a respective mean survival of 3.2 and 0.5 years. PDTC is a transitional step in the progression to ATC and presents intermediate characteristics in terms of differentiation and aggressiveness. Although some kinase inhibitors of the ERK (extracellular signal regulated protein kinase) pathway have been approved for the treatment of advanced thyroid carcinomas refractory to radioiodine uptake (Carneiro et al. 2015), the therapeutic response to these drugs is only temporary and relapse of the tumor due to the emergence of resistance is common. Additionally, systemic inhibition of the ERK pathway generates toxicity, especially in highly proliferative tissues. Currently, there is a lack of effective treatments for advanced thyroid carcinomas.

Thyroid cancer is essentially an ERK-driven carcinoma. $B R A F$ (rapidly accelerated fibrosarcoma type-B) mutations are found in up to $60 \%$ of PTC, followed by mutations in the different $R A S$ (rat sarcoma) isoforms (10-15\%) with a strong bias for NRAS, which are specially associated with FTC and the follicular variant of PTC (FV-PTC). Genetic rearrangements leading to ectopic expression of chimeric tyrosine kinase receptors (TKRs) such as RET (rearranged during transfection), ALK (anaplastic lymphoma kinase) and NTRK (neurotrophic receptor tyrosine kinase) can also be found in both PTC and FTC, with a higher frequency in children than in adults, and may be related to radiation exposure. In addition, genetic rearrangements in $P A X 8 / P P A R g$ (paired box8/peroxisome proliferator-activated receptor gamma) are also found at high rates in FTC and FV-PTC and in an exclusive manner with the aforementioned mutations, and hence, it is also considered an oncogenic driver. While the underlying transforming mechanism is poorly understood, it might be related to PPARg loss of function (Kroll et al. 2000). The high overall incidence of these mutations, their clonal nature and exclusive occurrence, provides strong evidence for the requirement of RAS/ERK activation at the onset of WDTC.

The initial $R A S$ or $B R A F$ mutation is central to the subsequent behavior of the tumors they give rise to. BRAF mutations confer strong activation of ERK, whereas RAS mutations provide weaker ERK activation, but allow activation of other relevant effectors involved in tumorigenesis such as PI3K (phosphatidylinositol 3-kinase) or RAC1 (ras-related C3 botulinum toxin substrate 1) (Cancer Genome Atlas Research Network 2014). These differences in signaling likely explain the intrinsic features of BRAF- and RAS-driven tumors - papillary pattern of growth, lower differentiation state and lymphatic dissemination with lymph node metastases in the former versus follicular growth pattern, higher differentiation state and hematogenous spread with distant metastases in the latter.

While there is no doubt that the aforementioned genetic lesions are driver mutations, they do not seem to confer aggressive properties to WDTC per se - most of these tumors are confined to the connective tissue capsule that encloses the gland, grow very slowly, present a silent genome in terms of mutation density and retain, to some extent, a differentiated state. This begs the question - how do these indolent tumors progress to overwhelmingly malignant advanced thyroid carcinomas?

Work from The Cancer Genome Atlas (TCGA) Network on PTC has greatly helped in identifying the oncogenic drivers responsible for PTC initiation (Cancer Genome Atlas Research Network 2014) and, together with other pan-genomic studies including large cohorts of patients with PDTC or ATC (Kunstman et al. 2015, Landa et al. 2016), has provided a model of progression based on genomic instability and a lack of genome control. From this large cohort of PTC, only seven genes were found mutated at a significant rate: $B R A F, N, K$, and $H R A S, E I F 1 A X$ (eukaryotic translation initiation factor 1A X-linked), CHEK2 (checkpoint kinase 2) and PPM1D (protein phosphatase, $\mathrm{Mg}^{2+} / \mathrm{Mn}^{2+}$ dependent $\left.1 \mathrm{D}\right)$. The last two encode for proteins involved in DNA repair and were found at a very low prevalence (1.2\%). Interestingly, alterations in these genes occurred concomitantly with ERK pathway mutations. An additional eight genes related to DNA repair were also found mutated $(6.5 \%$ overall) in a mutually exclusive manner, without reaching significance. Furthermore, the study identified mutations in 57 epigenetic regulatory genes. The bulk of PTC (72.9\%) presented a silent genome in terms of somatic copy-number alterations (SCNA) but, interestingly, 9.9\% of the tumors showed a $22 \mathrm{q}$ arm-level deletion that contains the CHEK2 and NF2 (neurofibromin 2) loci and was largely associated with FV-PTC. Loss of heterozygosity in this region has been related to enhanced RAS signaling through a mechanism involving the loss of function of the tumor suppressor NF2 and activation of the Hippo pathway effectors YAP1 (Yes-associated protein 1) and TEAD (TEA domain transcription factor) (GarciaRendueles et al. 2015). A hypothesis derived from these 
reports is that mutations activating the RAS/ERK axis, together with alterations in genes controlling the health and/or the epigenetic state of the genome, could be responsible for the subset of WDTC that progress to advanced thyroid carcinomas. A model of thyroid cancer progression including the most relevant data is depicted in Fig. 1.

The high rates of $B R A F$ and $R A S$ mutations in PDTC and ATC are strong indicators of their origin from WDTC. They are also found in an exclusive manner, reflecting their clonal origin and also indicating that a single mutation in one member of the pathway is sufficient not only for the onset of WDTC, but also for the progression to the aggressive variants. Mutations in genes related to DNA repair, epigenetic regulation and chromatin remodeling are also enriched in advanced tumors, again underscoring their involvement in tumor progression (Landa et al. 2016).

Mutations in other genes that synergize with RAS/ERK activation in conferring tumor aggressiveness can be found at high rates in advanced thyroid tumors. TERT (telomerase reverse transcriptase) promoter mutations can be found at relatively low rates in PTC, but are enriched in PDTC and ATC in a progressive manner (9, 40 and 73\%, respectively) (Cancer Genome Atlas Research Network 2014, Landa et al. 2016). Furthermore, they are frequently found together with $R A S$ and $B R A F$ mutations, conferring aggressiveness and poor prognosis. Mutations in the
TERT promoter generate de novo binding sites for ETS (E-twenty-six) transcription factors, which are activated by RAS/ERK signaling (Horn et al. 2013, Huang et al. 2013), explaining the synergy with BRAF mutations. This hypothesis has been recently demonstrated in human thyroid tumor-derived cell lines, where FOS activation by BRAFV60E increased the expression of the ETS transcription factor GABPB to selectively activate mutant TERT promoter (Liu et al. 2018). Increased TERT expression allows repeated cycles of cell division without shortening of telomeres, resulting in tumor cell immortality (Nakamura et al. 1997).

Mutations in EIF1AX are rare (1.5\%) but occur widely in PTC (Cancer Genome Atlas Research Network 2014). Interestingly, these mutations appear exclusively with established driver mutations such as $B R A F, R A S$ or RET/PTC, pointing to EIF1AX as a novel driver of WDTC. This exclusivity is lost in advanced thyroid tumors, where EIF1AX mutations are found at higher rates - 11\% in PDTC and 9\% in ATC - and, when found together with RAS mutations, result in an increased risk of recurrence and poor prognosis (Landa et al. 2016). The underlying mechanism has been linked to enhanced activation of the PI3K/mTOR (mechanistic target of rapamycin) pathway (Krishnamoorthy et al. 2019).

Mutations in different components of the PI3K pathway are also found in PDTC (11\%) and particularly in ATC (39\%), but with a very low prevalence in PTC
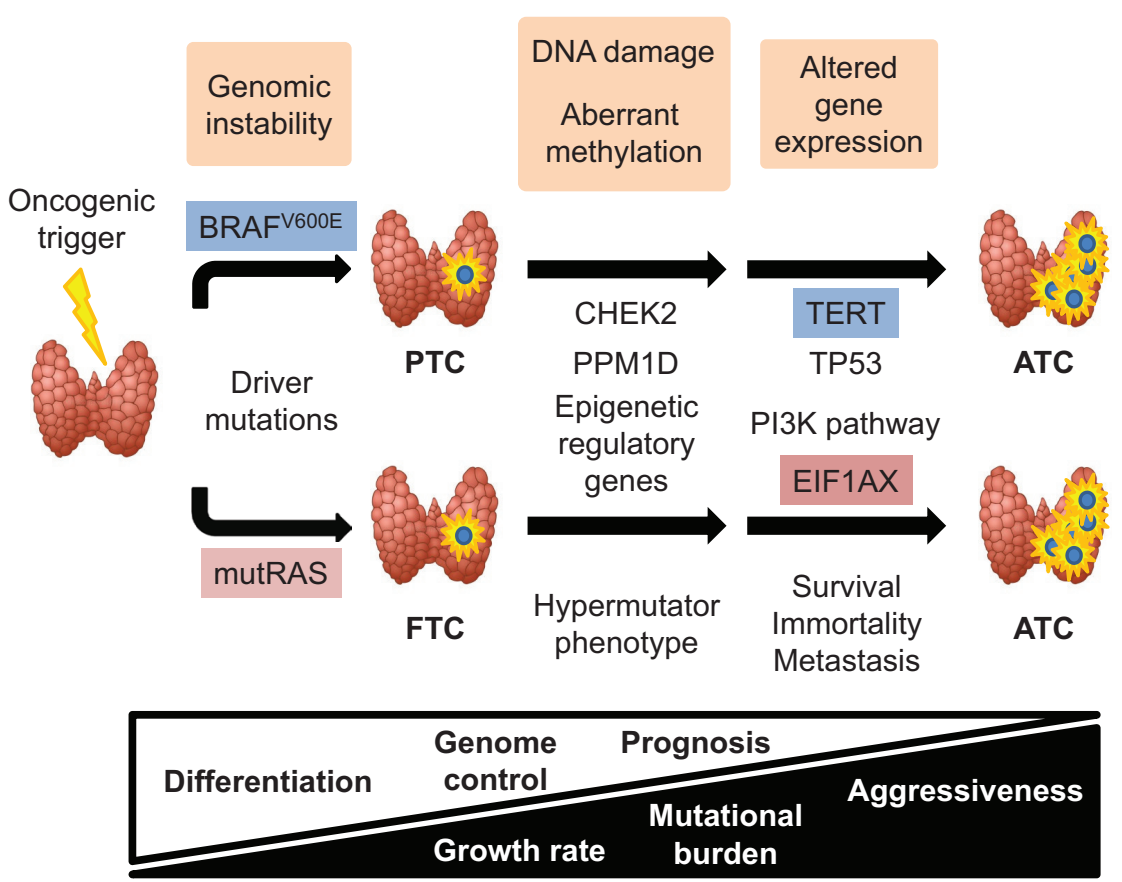

Figure 1

Model of thyroid cancer progression. An initial oncogenic trigger frequently induces mutations in the driver genes BRAF and RAS, which lead to the onset of papillary thyroid carcinoma (PTC) and follicular thyroid carcinoma (FTC), respectively. Those carcinomas are differentiated, and present a slow growth, a low mutational background and an excellent prognosis. However, they promote genomic instability. Secondary mutations in genes related to DNA repair (CHEK2 and PPM1D) and epigenetic regulation increase the mutational burden and alter general gene expression, conferring a hypermutator phenotype. Additional mutations in the TERT promoter, EIF1AX, TP53 or components of the PI3K pathway allow progression to advanced and metastatic carcinomas, with increased aggressiveness and growth rate and progressive loss of genome control and differentiation. TERT and $B R A F$, in blue, and RAS and EIF1AX mutations, in pink, synergize to promote progression to advanced thyroid carcinomas (c) 2019 Society for Endocrinology Published by Bioscientifica Ltd. Printed in Great Britain 
(4.5\%), suggesting that they might represent late genetic events related to tumor progression (Cancer Genome Atlas Research Network 2014, Landa et al. 2016; reviewed in Riesco-Eizaguirre \& Santisteban 2016).

The dependency of thyroid carcinomas on RAS/ERK activation has been exploited clinically by the use of inhibitors of the different kinases of the pathway. BRAF and MEK (MAP/ERK kinase) inhibitors have been approved for the treatment of RAIR (radioactive iodinerefractory) advanced thyroid carcinomas (Carneiro et al. 2015), supported by the encouraging results obtained in mouse models. The efficacy of these inhibitors is due to their capacity to impair ERK activation (Nagarajah et al. 2016). However, since they are administered systemically, this is often accompanied by undesirable side effects on highly proliferative tissues such as skin and the intestinal epithelial barrier. A necessary balance is thus required to reach an effective therapeutic threshold. Despite initial encouraging results, a lasting response to these drugs is, however, infrequently seen because of the emergence of resistance mechanisms that reactivate the pathway, leading to tumor relapse. This reflects the complexity of the RAS/ERK pathway, with multiple upstream regulators, downstream effectors, regulators that provide specific locations, multiple positive and negative feedback loops and crosstalk with other signaling pathways. Understanding the dynamics of activation, the mechanisms that confer specificity to the pathway, and their association with the tumorigenic process provides the basis for the inhibition of specific targets that may be essential for the establishment of the primary lesion or its dissemination. Theoretically, this selective approach would be less likely to trigger resistance mechanisms, and undesired toxic effects.

\section{The RAS/ERK pathway}

Mitogen-activated protein kinase (MAPK) pathways are evolutionary-conserved signaling cascades that link extracellular and internal stimuli to the control of multiple cellular processes both in physiological and pathological conditions, including cell adhesion, proliferation, survival, metabolism, migration, invasion, differentiation and gene transcription. Six different MAPK modules are known to exist in mammals. We will focus here on the RAS/ERK axis (Fig. 2), owing to its relevance for human and thyroid carcinogenesis.

In a prototypical scenario, a growth factor binds to its TKR, which undergoes auto-phosphorylation, allowing the binding of adaptor proteins that recruit RAS exchange factors to the membrane where they activate RAS proteins. There are four main RAS isoforms encoded by three independent genes, $N, H$ and KRAS (KRAS has two splicing variants, KRAS4A and $4 B$ ), with overlapping and specific functions, ubiquitous expression and high sequence homology except for the carboxyterminal hypervariable region (HVR), which is thought to determine specificity in signaling and functions (Prior \& Hancock 2012). RAS proteins use the HVR to bind to specific lipid microdomains of the plasma membrane and intracellular organelles.

All RAS proteins function as molecular switches that cycle between a GDP-bound, inactive state and a GTP-bound active state (Bos et al. 2007). Activation is facilitated by GEFs (guanine-nucleotide exchange factors)

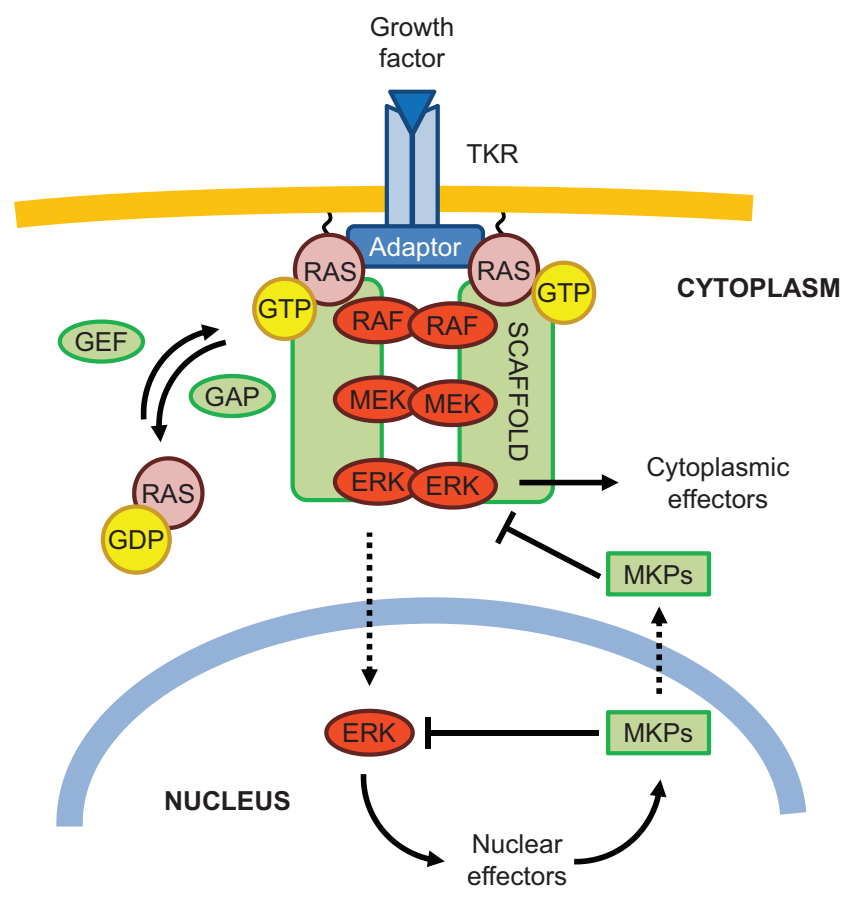

Figure 2

Overview of the RAS/ERK pathway. Upon growth factor binding, the tyrosine kinase receptor undergoes autophosphorylation creating binding sites for adaptor proteins that recruit RAS proteins to the membrane, allowing interaction with GEFs that promote GDP to GTP exchange and activation. GAPs promote inactivation by increasing intrinsic RAS-GTPase activity. Activated RAS induces the sequential activation of the kinase catalytic core formed by RAF, MEK and ERK, in a process dependent on dimerization. Activated ERK elicits a dramatic response both in the nucleus and cytoplasm, interacting with a myriad of effectors. Spatiotemporal activation is modulated by scaffold proteins of the pathway and negative regulation is driven by ERK-dependent expression of MKPs that dephosphorylate ERK in the nucleus and cytoplasm. Single arrows mean activation; blunt ends mean inactivation; double arrows indicate transition between two states; dotted lines indicate changes in subcellular localization.
C) 2019 Society for Endocrinology Published by Bioscientifica Ltd. Printed in Great Britain 
that promote GDP release from RAS proteins, allowing the incorporation of GTP. RAS affinity for GDP and GTP is similar, and binding to GTP is determined by the 10-fold higher cellular concentration of the latter. The GEF is released by conformational changes induced by GTP binding, and interaction with effectors proceeds. Inactivation is catalyzed by GAPs (GTPase-activating proteins) that increase intrinsic RAS GTPase activity, leading to GTP hydrolysis.

In human cancers, specific missense RAS mutations at codons 12, 13 or 61 decrease the affinity toward GAPs, leading to a constitutively GTP-bound active state (Prior et al. 2012). RAS is mutated in one-third of all human carcinomas (Bos 1988), with a relative frequency of $85 \%$, $12 \%$ and $3 \%$ for $K, N$ and $H R A S$, respectively. Accordingly, their inhibition has been the focus of intense research for more than three decades. Strategies directed at RAS membrane binding, and to the synthesis of GTP analogs or molecules designed to bind the RAS catalytic pocket, have been unsuccessful, and the inhibition of downstream effectors is currently the main subject of research (Cox et al. 2014). Once activated, RAS promotes downstream activation of up to 11 families of effectors, and six of them have been implicated in RAS tumorigenic effects (Pylayeva-Gupta et al. 2011).

Possibly the best studied RAS effectors involved in human cancer are the RAF proteins, a family of serine/ threonine kinases composed of three members in mammals -ARAF, BRAF and CRAF (RAF1) - which are located at the origin of the three-tiered cascade that leads to ERK activation. Insights gained from gene-knockout studies in mice have shown that all three RAF isoforms fulfill both overlapping and non-redundant functions (Pritchard et al. 1996, Wojnowski et al. 1997, Huser et al. 2001, Mikula et al. 2001). BRAF presents the highest basal kinase activity (Mason et al. 1999) and is the most frequently mutated isoform in human cancer (Davies et al. 2002). Indeed, more than 40 different activating mutations in BRAF are known, although the most frequent is the V600E substitution in the activation loop, which accounts for 90-95\% of all BRAF mutations (Dankner et al. 2018). CRAF and ARAF have been also found mutated in tumors but a much lower rate. RAF proteins are activated in an intricate and not well-understood process that involves phosphorylation and de-phosphorylation of different residues, conformational changes and formation of dimeric complexes (Lavoie \& Therrien 2015). Several drugs targeting BRAFV600E have been approved for the treatment of metastatic melanoma and RAIR-advanced thyroid carcinomas. Although the response rate is initially high, relapse of the tumors is largely inevitable due to innate and acquired drug resistance mechanisms (Mandal et al. 2016).

There are two major effectors described for RAF proteins - MEK1 and MEK2 - that are respectively activated by phosphorylation on Ser218/Ser222 and Ser222/Ser226 in the activation segment (Kyriakis et al. 1992). Once activated, MEKs activate their only known substrates, ERK1 and ERK2, also by phosphorylation, on Thr202/Tyr204 and Thr185/Tyr187, respectively, in the TEY (Thr-Glu-Tyr) motif at the activation loop (Ray \& Sturgill 1988, Roskoski 2012). More than 200 effectors have been described for ERK proteins, both in the nucleus and cytoplasm, reflecting their ability to control many different aspects of cell biology (Yoon \& Seger 2006, Zaballos \& Santisteban 2017).

ERK activation is tightly controlled by at least 15 scaffold proteins. By definition a scaffold is a protein that binds simultaneously to at least two members of the same signaling pathway. Scaffold proteins fine-tune signals by regulating their amplitude, intensity and timing, while isolating them from interference with other signaling pathways. They also provide spatial selectivity to the signals by confining them to specific subcellular localizations (Calvo et al. 2010). Signal flux through the ERK pathway is shut down, or attenuated, by immediate negative feedback loops, and by phosphatases that inactivate the different kinases of the cascade in a gradual manner through dephosphorylation of the activating residues (Keyse 2000).

Most of these spatiotemporal regulators are not usually found mutated in human cancer, although alterations in their expression are commonly associated with different tumor types. The idea of targeting proteinprotein interactions in the RAS/ERK pathway, rather than kinase activities, has been proposed as an alternative therapeutic strategy and several approaches have already proven successful at the preclinical level (Garcia-Gomez et al. 2018). ERK dimerizes upon phosphorylation of the activation loop, which is essential for extranuclear signaling, and preventing this process with smallmolecule inhibitors impairs activation of cytoplasmic but not nuclear ERK effectors and decreases tumor growth of melanoma cells in a xenograft mouse model (Herrero et al. 2015). Interestingly, ERK dimerization inhibitors are unaffected by resistance mechanisms that impair BRAF and MEK inhibitors (Herrero et al. 2015). This illustrates how targeting a protein-protein interaction can yield therapeutic effects.

The RAS/ERK pathway offers multiple potential therapeutic targets. We will next describe the main RAS 
GAPs and GEFs, the scaffold proteins of the pathway and the negative feedback mechanisms involved in the inactivation of this important signaling cascade (Fig. 2), which could be exploited for therapeutic intervention, with special attention to data pertaining to thyroid cancer.

\section{RAS GEFs and GAPs}

All small GTPase cycles between an inactive (GDP-bound) state and an active (GTP-bound) state. GTPases possess several structural features to accomplish these functions (Fig. 3A). They harbor a ' $G$ domain' in the N-terminal region, composed of five distinctive G-boxes, G1-G5. G1, also known as P-loop (Saraste et al. 1990), is a purine nucleotide binding region. The G2 box is necessary for the functioning of the switch I region that plays an important role in the interaction with effector proteins (Spoerner et al. 2001). The function of the G3 box is related to the union and orientation of the catalytic $\mathrm{Mg}^{2+}$ ion and the reactive water molecule, acting as a sensor for the conformational change of the switch II region. The G4 region makes hydrogen bond contact with the guanine ring, which confers specificity for guanine
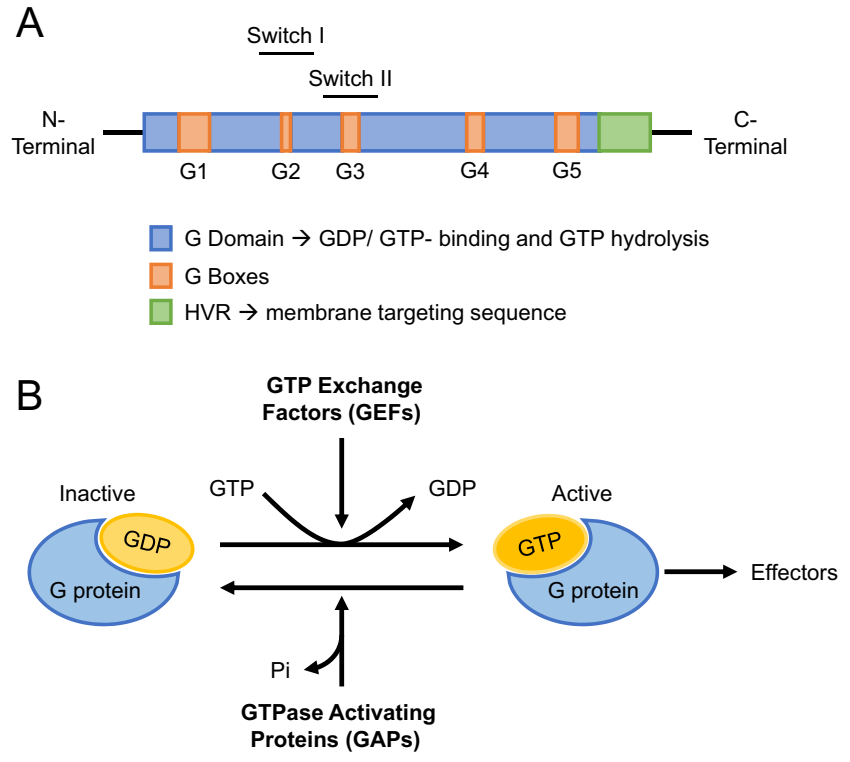

Figure 3

$\mathrm{G}$-protein domains and activation cycle. (A) Functional domains of small G proteins. From the $\mathrm{N}$-terminus, residues $1-166$ comprise the $\mathrm{G}$ domain, containing the consensus sequences for the GDP/GTP-binding motifs. There are two regions inside the $\mathrm{G}$ domain important for the conformational change in the GDP/GTP cycle, termed switch I and switch II. The C-terminal region contains a hypervariable region, which determines plasma membrane anchoring. (B) The Ras GTPase cycle. The RAS proteins cycle between an inactive (RAS-GDP) and an active (RAS-GTP) state, regulated positively by GEFs (guanine exchange factors) and negatively by GAPs (GTPase-activating proteins).

(c) 2019 Society for Endocrinology Published by Bioscientifica Ltd. Printed in Great Britain nucleotides. Finally, the amino acids in the G5 box form indirect associations with the guanine nucleotides, which stabilize this union (Dever et al. 1987, Colicelli 2004). In addition, RAS shares two common domains important for the correct activation and function of the GTPase the switch I and switch II regions. These domains change their structure in response to the transition from the GTPbound to the GDP-bound state (Fiegen et al. 2006). Finally, a HVR is located at the C-terminus. As its name suggests, this region is the least homologous among the members of the family. The HVR contains the information necessary for all post-translational modifications that RAS proteins undergo during their maturation and is necessary for RAS binding to membranes, thereby dictating the protein localization within the cell (Wennerberg et al. 2005).

\section{RAS GEFS}

Under physiological conditions, the RAS activation cycle is exquisitely regulated by GEFs and GAPs (Fig. 3B). There are specific GEFs and GAPs for each GTPase family (Fig. 4), but the mechanisms of action are mostly quite similar (Vigil et al. 2010). GEF proteins catalyze nucleotide dissociation from the GTPase by sterically displacing the

\section{A RAS GEFs}

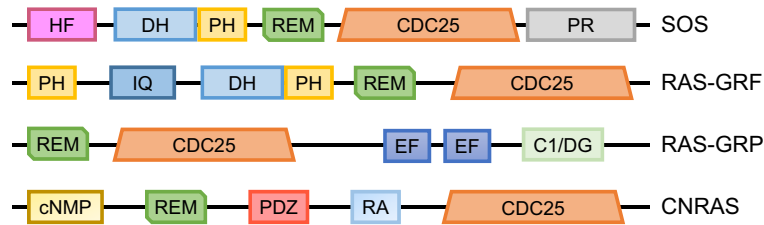

\section{B RAS GAPs}

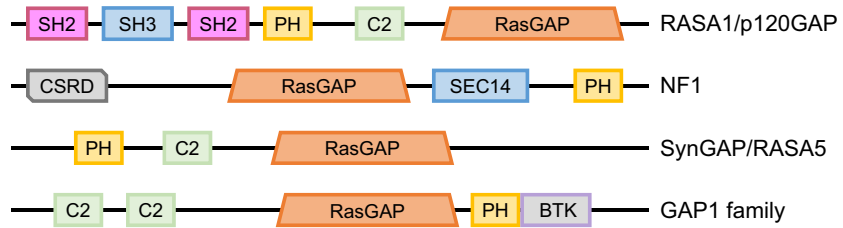

\section{Figure 4}

Representative RAS GEFs and RAS GAPs. The catalytic domain, either the GEF or the GAP domain, is highlighted in orange. (A) Domain structure of RAS GEFs. The different domains are as follows (in order of appearance): HF (histone folding motif), DH (Dbl-homology), $\mathrm{PH}$ (pleckstrin homology), REM (ras exchange motif), PR (proline-rich domain), IQ (calmodulinbinding domain), EF (Ca2+ binding domain), C1 (DAG-binding C1 domain), Ras-association (RA), PDZ and cNMP (CAMP/cGMP) binding (CNMP-BD) domains. (B) Domain structure of RAS-GAPs. The different domains are as follows (in order of appearance). $\mathrm{SH} 2$ and $\mathrm{SH} 3$ are domains with homology to the regions 2 and 3 of Src, $\mathrm{PH}$ (pleckstrin homology), C2 (high-affinity $\mathrm{Ca}^{+2}$-dependent phospholipid binding domain), CSRD (cysteine and serine-rich domain), SEC14 (a lipid-binding domain) and BTK (Bruton's tyrosine kinase motif). 
$\mathrm{Mg}^{2+}$ ion and triggering conformational changes on the switch I and switch II regions and the P-loop, which promotes the dissociation of the GDP nucleotide and, subsequently, the release of the GEF itself. Once the GEF is released, the tendency to recover the native conformation restitutes RAS nucleotide affinity and because the cellular concentration of GTP is 10-50-fold higher than that of GDP, the replacing nucleotide will be usually GTP. The incorporation of GTP induces a conformational change in the switch I and II regions, exposing the effector domain and thereby facilitating its interaction with effector molecules (Hall et al. 2002).

In mammals, four different GEF families are known to promote nucleotide exchange in RAS: SOS, RASGRF, RASGRP and CNRAS (Fig. 4A). The SOS (son of sevenless) family is composed of two members, SOS1 and SOS2, similar to the RASGRF family (RASGRF1 and 2), whereas the RASGRP family has four isoforms and CNRAS is unique. All four families have a CDC25 domain in common, which was initially described in Saccharomyces cerevisiae (Broek et al. 1987) and harbors the catalytic activity responsible for nucleotide exchange. Also within this region is the REM (RAS exchange motif), which is important for stabilizing binding to RAS (De Hoog et al. 2001). In addition to these motifs, a broad range of domains can also be found in the different GEF families. These mostly serve regulatory roles, orchestrating interactions with proteins and ions and playing important roles in cellular sub-localization (Pham et al. 2000, Rojas \& Santos 2006).

\section{RAS GEFs in cancer}

Since GEFs are the major contributors to small GTPase activation under physiological conditions, it is hardly surprising that their deregulation can contribute to human neoplasia. Strikingly, whereas GEFs for RHO GTPases often appear mutated and behave as bona fide oncogenes in human neoplasias, this is rarely the case for RAS GEFs (Bustelo 2018). For instance, in hereditary gingival fibromatosis type 1, a pre-neoplastic condition, a cytosine insertion in exon 21 of the SOS1 gene causes an overgrowth of the gingiva (Hart et al. 2002). Similarly, it has been reported that missense mutations in SOS1 have a causal relationship with Noonan syndrome, a developmental disorder characterized by short stature, facial dysmorphia, congenital heart defects, skeletal anomalies and augmented tumor frequency (Tartaglia et al. 2007). This finding suggested a possible role for SOS1 as an oncogene. However, further sequencing endeavors in a broad spectrum of primary malignancies determined that SOS1 missense mutations were present only in an insignificant number of cases (Swanson et al. 2008), arguing against the role of SOS1 as a driver oncogene in human cancers.

While not directly involved in cellular transformation, RAS GEFs are clearly involved in other processes relevant to carcinogenesis. For example, RASGRF1 expression correlates with that of matrix metallopeptidase-9 (MMP9) and with enhanced metastatic capabilities of human melanoma cells (Zhu et al. 2007). A similar role has been proposed for RASGRF2 in controlling migration and invasion by modulating MMP9 through SRC/PI3K and NFkB pathways (Lu et al. 2018). RASGRF2 has been implicated in metastasis and invasion also in melanoma cells by regulating the transition between ameboid and mesenchymal movement via inhibition of CDC42 (cell division cycle 42) (Calvo et al. 2011). A RASGRF2-GM130 (Golgi matrix protein $130 \mathrm{kDa}$ ) complex inhibiting CDC42 signaling has also been implicated in cellular polarity and is lost in breast and colorectal tumors (Baschieri et al. 2014). In another context, low expression of RASGRF2 is associated with aberrant methylation patterns in human non-small-cell lung cancer (Fernandez-Medarde \& Santos 2011).

Regarding the RASGRP family, RASGRP3 contributes to the malignant phenotype of prostate cancer cells as its downregulation inhibited cell proliferation, impeded cell migration and induced apoptosis (Yang et al. 2010a). Suppression of RASGRP3 in melanoma cells has been linked to the inhibition of cell proliferation and decreased tumor xenograft growth in immunodeficient mice. Moreover, overexpression of RASGRP3 in human primary melanocytes caused alterations in cellular morphology, enhanced cell proliferation and promoted tumorigenesis in a mouse xenograft model (Yang et al. 2011). Aberrant expression of RASGRPs has been detected in hematopoietic malignancies, such as acute myeloid leukemia (AML) (Ksionda et al. 2013). RASGRP4 has transforming potential in fibroblast or epithelial cells, and when overexpressed in myeloid cells in the presence of phorbol esters, RASGRP4 promotes cytokine-independent growth (Reuther et al. 2002, Ksionda et al. 2013). A possible role for RASGRP4 in leukemogenesis has been suggested by the finding that RASGRP4 overexpression in a mouse bone marrow transplantation model results in AML-like characteristics (Watanabe-Okochi et al. 2009).

To date, there is scarce evidence for the involvement of RAS GEFs in thyroid malignancies. However, this likely reflects an understudied field rather than a discordant behavior compared with other tissues. 


\section{RAS GAPs}

Even though RAS proteins exhibit an intrinsic capacity for hydrolyzing GTP, this is a slow reaction, of about $30 \mathrm{~min}\left(\sim 4 \times 10^{-4} / \mathrm{s}\right)$ (Trahey \& Mccormick 1987). RAS GAPs accelerate this reaction by several orders of magnitude (Allin et al. 2001). Structural studies have demonstrated that all hitherto known GAPs function in a similar fashion - by inserting a highly conserved arginine residue, the arginine finger, into the RAS active site (Ahmadian et al. 1997). This structural change results in an augmented net positive charge of the pocket, facilitating the nucleophilic attack undertaken by the reactive water molecule, associated with the conserved Gln61 residue, thereby enabling the cleavage of the gamma-betaphosphoanhydride bond in GTP. This mechanism of action also provides an explanation for the constitutive activity and oncogenicity of RAS mutants harboring mutations in Gln61, based on their unresponsiveness to GAPs (Scheffzek et al. 1997, Vetter \& Wittinghofer 2001).

Mammals express five families of GAPs, of which the best characterized are RASA1/p120GAP, NF1 and GAP1 (Fig. 4B). All of them possess a highly conserved RAS-GAP catalytic domain where the arginine finger is located (Fig. 4). Also included in this region is the alpha7 variable loop, which determines the specificity of RAS-GAP binding and the invariant FLR (phenylalanineleucine-arginine) motif, which forms a scaffold that stabilizes RAS switch regions, contributing to the stimulation of the GTPase activity (Ahmadian et al. 2003, Rojas \& Santos 2006). In addition, RAS GAPs also have a number of different domains, including CSRD (cysteine and serine-rich domain), $\mathrm{PH}$ (pleckstrin homology), Sec14 lipid-binding domain, SH2 (Src homology 2) and SH3 domains. All these domains are involved in regulatory functions, mostly involving protein-protein and proteinlipid interactions (Rojas \& Santos 2006).

\section{RAS GAPs in cancer}

In contrast to the limited evidence on RAS GEFs participation in cancer, the involvement of GAPs in carcinogenic processes is well established.

Fibroblasts deficient for RASA1/p120GAP exhibit hyperactivation of the RAS/ERK pathway, but not abnormal cell proliferation. Similarly RASA1-deficient mice do not have an increased incidence of tumors (Henkemeyer et al. 1995, Koehler \& Moran 2001), which suggests that RASA1/p120GAP may be involved in RAS downregulation in physiological processes other than mitogenic signaling. Accordingly, RASA1 mutations in human tumors are scarce, at best (Friedman et al. 1993).

In contrast to RASA1, neurofibromin 1 (NF1), another GAP for RAS, is clearly implicated in carcinogenic processes, acting as a tumor suppressor. Loss-of-function mutations in NF1 underlie neurofibromatosis type I syndrome, characterized by elevated RAS-GTP levels and an increased incidence of tumors (Yang et al. 2006). Furthermore, somatic inactivation of NF1 is often detected in a broad spectrum of tumors, including lung carcinoma (Ding et al. 2008), several leukemias (BoudryLabis et al. 2013), ovarian (Sangha et al. 2008) and breast (Dischinger et al. 2018) cancer and glioblastoma (Parsons et al. 2008). The implication of NF1 in melanoma has also been widely studied after the discovery of a homozygous NF1 deletion in 1993 (Andersen et al. 1993). Since then, several studies have reported a significant frequency of somatic NF1 mutations in melanoma (Nissan et al. 2014, Krauthammer et al. 2015, Ratner \& Miller 2015). In the case of thyroid cancer, NF1 mutations are found at a very low prevalence in PTC (0.5\%) in tumors lacking any other known driver mutation (Cancer Genome Atlas Research Network 2014). Interestingly this increases up to $9 \%$ in ATC (Landa et al. 2016). Furthermore, NF1 mutations have been associated with acquired resistance to HRAS inhibition in an advanced thyroid cancer mouse model (Untch et al. 2018).

More recently, another RAS GAP, DAB2IP (DAB2 interacting protein), has been reported to act as a tumor suppressor in prostate cancer (Wu et al. 2014) and hepatocellular carcinoma (Zhang et al. 2012). In this respect, reduced DAB2IP expression as a consequence of aberrant promoter methylation has been shown in prostate (Chen et al. 2003), gastrointestinal (Dote et al. 2005), lung (Yano et al. 2005) and breast (Dote et al. 2004) cancers. Another RAS GAP with a tumor suppressor role in some types of cancer is RASAL1, a calcium-regulated GAP. RASAL1 is silenced through CpG methylation in multiple tumors including thyroid, colorectal and hepatocellular tumors (Xing 2007, Ohta et al. 2009, Calvisi et al. 2011). Thyroid tumor cells, both of follicular and papillary origin, express low levels of EBP1 (ERBB3-binding protein 1), which interacts with ERBB3 (erb-b2 receptor tyrosine kinase 3 ) receptors, acting as a tumor suppressor. Overexpression of EBP1 resulted in enhanced expression of RASAL1 and attenuation of tumor cell growth, whereas RASAL1 knockdown abrogated the effects of forced EBP1 expression on cell growth, migration and invasiveness of thyroid tumor cells (Liu et al. 2015).
C) 2019 Society for Endocrinology Published by Bioscientifica Ltd. Printed in Great Britain 


\section{Scaffold proteins}

A variety of extracellular stimuli converge on the MAPK pathway to elicit a broad spectrum of cellular responses. To achieve signal diversity and specificity, the spatiotemporal flux through the pathway is organized by scaffold proteins, which recruit different components of the MAPK pathways to form complexes that optimize signal transmission (Fig. 5).

Saccharomyces cerevisiae Ste5p was the first MAPK scaffold to be identified, and was shown to tether three kinases, Ste11 (MAP3K), Ste7 (MAP2K) and Fus3 (MAPK) in the mating response to pheromones (Choi et al. 1994). A number of mammalian scaffolds controlling ERK activation have now been identified. In this section, we describe a few of the most representative scaffold proteins of the RAS/ERK pathway (Fig. 6), with special attention to their role in human cancer.

\section{Kinase suppressor of RAS}

Kinase suppressor of RAS (KSR) is probably the best characterized of the ERK scaffolds in mammals. It was initially described in Drosophila melanogaster and Caenorhabditis elegans as a positive regulator of Ras (Kornfeld et al. 1995, Therrien et al. 1995). Two different isoforms have been identified in mammals, KSR1 and KSR2, which share $61 \%$ amino acid identity. KSR1 contains five different domains, termed CA1-CA5. The N-terminal

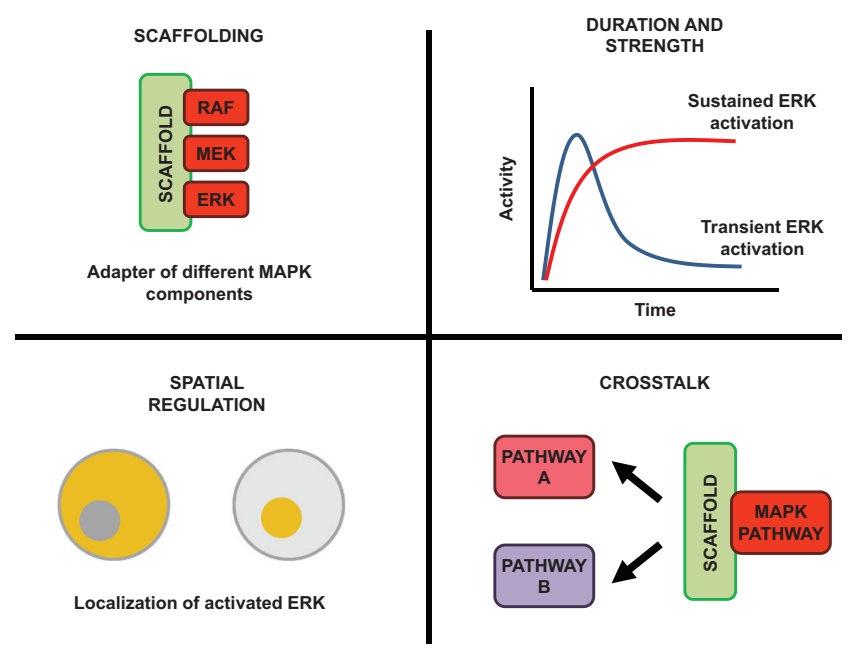

\section{Figure 5}

Functions of scaffold proteins. Scaffold proteins localize different members of the MAPK pathway, optimizing activation and inactivation and providing isolation from other signaling pathways. Through these interactions scaffolding proteins control the amplitude and time of activation of the pathway, and provide specific subcellular localization and points of crosstalk with other signaling pathways.

(c) 2019 Society for Endocrinology Published by Bioscientifica Ltd. Printed in Great Britain
CA1 domain contributes to BRAF and membrane binding, CA2 is a proline-rich domain with no described function, CA3 is a cysteine-rich domain that mediates membrane binding and CA4 presents a motif for interaction with ERK. Finally, the CA5 region includes a putative kinaselike domain, although it is still unclear whether it actually displays kinase activity (Frodyma et al. 2017). Single knockout mice Ksr1 and Ksr2 show different phenotypes, indicating that the proteins fulfill independent functions (Lozano et al. 2003, Costanzo-Garvey et al. 2009). $\mathrm{Ksr}^{-1-}$ mice are fertile and develop normally, whereas $\mathrm{Ksr}^{-/-}$mice present reduced fertility and spontaneous obesity. Interestingly $\mathrm{Ksr}^{-/-}$mice are resistant to Ras-driven tumorigenesis.

KSR1 assembles RAF, MEK and ERK at lipid rafts through a tightly regulated mechanism. In resting cells, KSR1 is found in the cytoplasm in complex with the 14-3-3 protein and the E3 ubiquitin ligase IMP (impedes mitogenic signal propagation). Cytoplasmic retention of KSR1 depends on c-TAK1 phosphorylation on Ser392 and Ser297, which provides docking sites for 14-3-3 (Muller et al. 2001). Upon growth factor stimulation, RAS induces proteasome-mediated IMP degradation and PP2Amediated KSR1 dephosphorylation on Ser392 (Ory et al. 2003, Matheny et al. 2004), leading to the release from 14-3-3 and relocation to the plasma membrane where KSR1 mediates MEK activation by RAF (Lavoie et al. 2018). Upon activation, ERK phosphorylates KSR1 in different residues, inducing its release from the plasma membrane and impairing signal transduction (Mckay et al. 2009).

KSR1 participates in tumorigenesis in various types of cancer, including skin, colorectal, breast, lung and pancreatic carcinoma. In KRAS-driven pancreatic and lung carcinomas, KSR1 downregulation by antisense oligonucleotides reduced xenograft tumor growth in nude mice (Xing et al. 2003). Also, Ksr1 depletion inhibited proliferation of HRas-dependent skin tumors in mice (Lozano et al. 2003). Conversely, KSR1 has been described as a tumor suppressor in breast cancer, where its expression positively correlates with overall and diseasefree survival. Furthermore, KSR1 overexpression inhibited tumor growth in mice, by stabilizing BRCA1 and inhibiting p53 transcriptional activity in a manner independent of ERK activation (Stebbing et al. 2015). Finally, expression of KSR1 plays a potential role in chemotherapy response in breast cancer, by enhancing cisplatin-induced ERK activation and cisplatin sensitivity (Kim et al. 2005). The role of KSR1 in thyroid cancer remains largely unknown, although KSR1 downregulation has been associated with decreased NOTCH signaling, downregulation of genes 


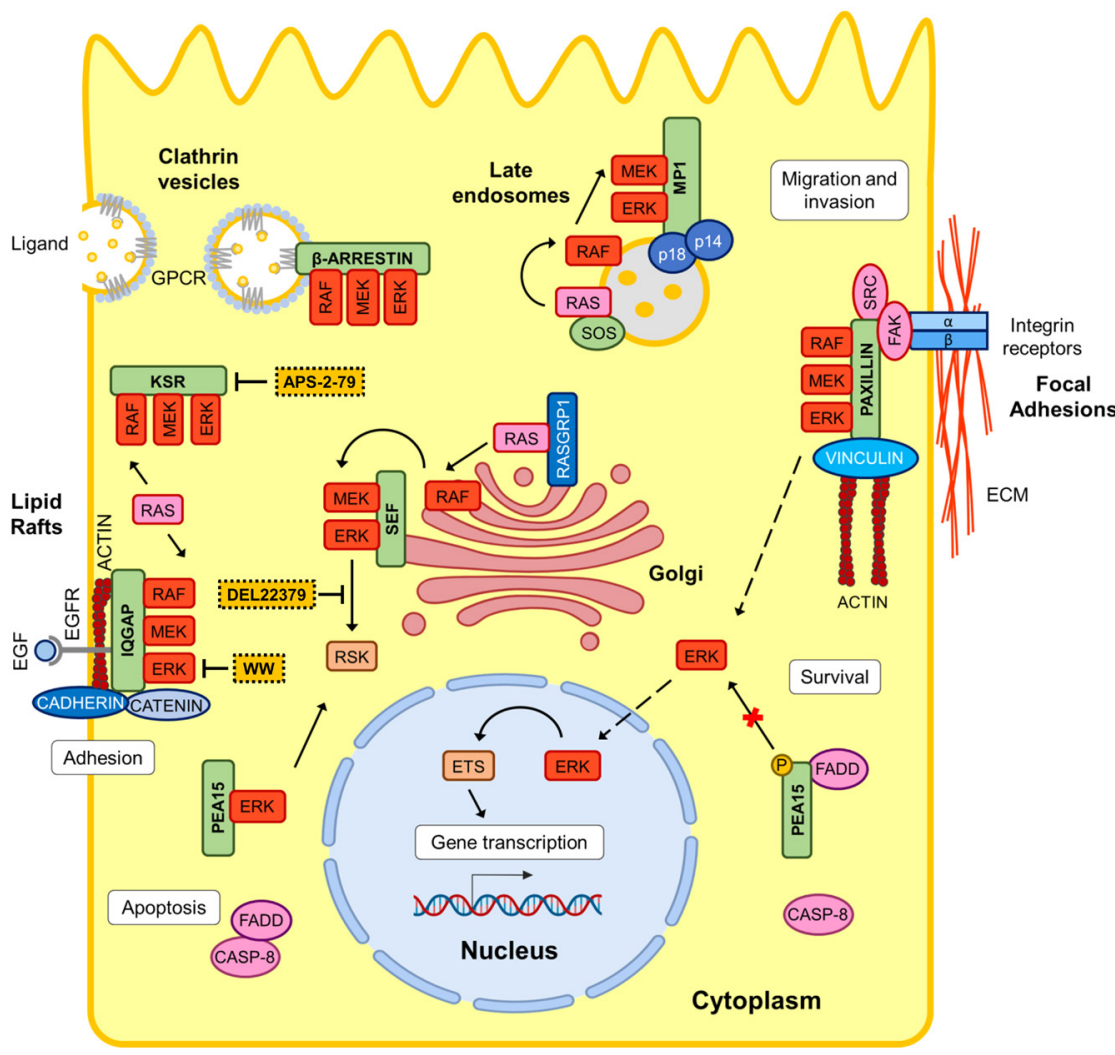

\section{Figure 6}

Scaffolds of the MAPK pathway. Scaffold proteins target MAPK complexes to different subcellular localizations to interact with specific sets of regulators and effectors to control diverse cellular processes. Arrows indicate activation; blunted lines mean inactivation; dashed lines indicate changes in subcellular localization. APS-2-79, WW and DEL22379 are inhibitors of KSR2, IQGAP1 and ERK dimerization respectively, that have been used in preclinical models. Figure created with BioRender.io (Toronto, Canada). related to oxidative phosphorylation and ERK inactivation in PTC (Lee et al. 2015).

Beyond the ERK pathway, KSR2 seems to be involved in the control of energy homeostasis through AMPK activation, favoring the transformed phenotype of tumor cells (Costanzo-Garvey et al. 2009, Fernandez et al. 2012). In agreement, mutations in KSR2 are associated with obesity, insulin resistance and impaired cellular fatty acid oxidation (Pearce et al. 2013).

The mild phenotype of $K s r 1^{-/-}$mice indicates that KSR1 is not essential for the adult, but it is required for RAS-driven transformation, making it an attractive therapeutic target. KSR1 levels can determine the response to RAF inhibitors. It has been described that RAF inhibitors trigger paradoxical ERK activation by inducing BRAF/CRAF heterodimerization in the presence of active RAS (Poulikakos et al. 2010). KSR1 competes with CRAF for BRAF binding in the presence of RAF inhibitors, reducing ERK activation and altering the effects of RAF inhibitors (Mckay et al. 2011).

In a different therapeutic approach, APS-2-79, a molecule that stabilizes KSR2 in an inactive conformation, impaired MEK phosphorylation by RAF and increased the therapeutic response of MEK inhibitors in RAS-mutant cells (Dhawan et al. 2016).

\section{IQ motif-containing GTPase-activating protein}

The IQ motif-containing GTPase-activating proteins (IQGAP) are a conserved family of scaffolding proteins comprising three members in most vertebrates: IQGAP1, IQGAP2 and IQGAP3. These are multidomain adapter proteins that interact with up to 100 different protein partners to control a wide range of cellular processes. The different isoforms fulfill independent functions and present specific patterns of tissue expression and subcellular localization (Hedman et al. 2015).

The best described functions for IQGAPs have been associated with the regulation of cytokinesis, cell polarity, migration and cell-cell adhesion, through control of the cytoskeleton. This is achieved through binding to F-actin, small GTPases such as RAC1 and CDC42 and proteins involved in cell contacts such as cadherins and catenins (Watanabe et al. 2015). Their role as scaffolds of the ERK pathway has also been well established, and it has been reported that IQGAP1 binds BRAF, MEK1/2 and ERK1/2, which is necessary for signaling downstream of epidermal growth factor (EGF) receptor (EGFR) (Roy et al. 2004, 2005, Ren et al. 2007). The distinct functions of the different isoforms may be partially explained by the differential binding to effectors; for instance, 
IQGAP1 can bind ERK1 and 2, whereas IQGAP3 only binds ERK1 (Yang et al. 2014).

IQGAP1 has recently been identified as an important PI3K pathway scaffold and may function as a switch between ERK and AKT activation. IQGAP1 binds different proteins involved in the generation of $\mathrm{PI}, 4,5 \mathrm{P}_{3}$ (phosphatidylinositol-3,4,5-trisphosphate) from phosphatidylinositol (Choi et al. 2016). The main PI3K effectors, AKT and PDK1 also bind IQGAP1, providing a platform for optimal pathway activation. Interestingly, the binding sites for PI3K and ERK components overlap and therefore the binding of the former excludes the binding of the latter. A recent report indicates that FOXO1 (forkhead box O1) is a major determinant of IQGAP1-mediated ERK activation (Pan et al. 2017). The FOXO1 transcription factor is regulated by AKT phosphorylation-dependent nuclear exclusion. Cytoplasmic, phosphorylated FOXO1 binds IQGAP1, leading to dissociation of the ERK pathway components from the complex (Pan et al. 2017). FOXO1 expression is diminished in thyroid cancer (Zaballos \& Santisteban 2013), consistent with its role as a tumor suppressor. Therefore, the possibility exists that FOXO1 downregulation primes ERK over PI3K activation in these tumors.

IQGAP1 is upregulated in multiple types of human tumors, including breast (Jadeski et al. 2008), pancreatic (Wang et al. 2013), ovary (Dong et al. 2006) and PTC (Liu et al. 2010), among others. Interestingly, the expression of the protein in different tumors is higher in invasive areas than in the tumor center or in healthy tissue, and increased IQGAP1 membrane localization has been associated with the loosening of cell-cell contacts and cell adhesion required for gastric cancer cell spreading (Takemoto et al. 2001). Genetic copy gain of IQGAP1 is frequent in thyroid cancer and increases in parallel with tumor aggressiveness, whereas IQGAP1 depletion in human thyroid cancer-derived cell lines prevents invasion and colony formation (Liu et al. 2010). High IQGAP1 expression in GBM (glioblastoma multiforme) defines a group of aggressive cells with stem-like properties (Balenci et al. 2006). The tumorigenic properties conferred by IQGAP1 establish this protein as an attractive therapeutic target, an idea that has been explored in a skin carcinoma mouse model (Jameson et al. 2013). In this study, Iqgap1null mice were resistant to Hras-driven skin chemical carcinogenesis. IQGAP1 binds ERK1/2 through a conserved WW domain, and a peptide containing the IQGAP1 WW motif inhibited RAS- and RAF-driven tumorigenesis and bypassed acquired resistance to BRAF inhibitors (Jameson et al. 2013). Interestingly Iqgap $1^{-/-}$mice develop normally
(Li et al. 2000) and therefore a high toxicity of IQGAP1targeted approaches is not expected.

Unlike IQGAP1, IQGAP2 expression is reduced in many different tumors where it is associated with poor prognosis, pointing to its role as a tumor suppressor (Kumar et al. 2017). Loss of expression of IQGAP2 has been related to promoter hypermethylation in ovarian and gastric carcinomas (Jin et al. 2008, Deng et al. 2016). Furthermore Iqgap2-- mice develop late-onset hepatocellular carcinoma (Schmidt et al. 2008), supporting a role for IQGAP2 in tumor suppressive functions. Interestingly, loss of Iqgap 2 expression was accompanied by an increase in Iqgap1 expression and activation of the Wnt/bcatenin pathway. In thyroid cancer, nuclear bcatenin is observed in cells that harbor RAS but not BRAF mutations and contributes to tumor progression (Sastre-Perona et al. 2016); however, a possible involvement of IQGAPs has not yet been addressed.

\section{Paxillin}

Paxillin is a multidomain adapter protein associated with focal adhesion (FA) sites - the points of connection between transmembrane integrins and components of the extracellular matrix (ECM) - where it is essential for FA turnover required for cell adhesion, migration and invasion. Growth factors and integrin-dependent adhesion to ECM induce paxillin phosphorylation at multiple sites, providing docking elements for proteins involved in FA dynamics such as FAK, SRC, talin and vinculin, among others. FAK and SRC phosphorylate paxillin in different tyrosine residues, allowing downstream activation of signaling pathways (Deakin \& Turner 2008). Paxillin has been described as an ERK scaffold owing to its ability to bind CRAF, MEK1 and ERK1/2 and to mediate ERKinduced cell spreading in response to hepatocyte growth factor. In resting conditions, paxillin is associated with MEK at FA. Upon hepatocyte growth factor stimulation, SRC phosphorylates Tyr118 on paxillin allowing ERK binding followed by RAF recruitment and pathway activation (Ishibe et al. 2003, 2004). In turn, activated ERK phosphorylates paxillin on several serine residues, leading to disassembly of the complex and ERK-paxillin nuclear translocation where both proteins cooperate to induce gene transcription in prostate cancer (Sen et al. 2012). Activation of intracellular pathways mediated by paxillin ultimately leads to the regulation of RHO family proteins at FAs allowing the control of cytoskeleton dynamics necessary for cell movement (Chen et al. 2005). Thus, by serving as a docking platform for FA-associated kinases, 
phosphatases and other proteins, paxillin links cell adhesion to different intracellular signaling complexes and the control of the cytoskeleton to promote cell migration and invasion.

Cell adhesion to the ECM is essential for survival and dissemination of tumor cells. Because paxillin is involved in signal transduction from the ECM, its role in tumor progression has been examined in different types of human carcinomas. Indeed paxillin was identified in fibroblasts as a protein that undergoes multiple tyrosine phosphorylation events upon transformation by $v$-Src (Glenney \& Zokas 1989). Increased paxillin expression and phosphorylation is associated with the progression of colorectal (CRC) (Yang et al. 2010b), prostate (Sen et al. 2012) and lung (Mackinnon et al. 2011) carcinomas, among others. In the lung, overexpression of paxillin through genomic amplification is found from the earliest to metastatic stages of lung cancer development (Mackinnon et al. 2011). However, this may be tumor dependent, since paxillin expression is low in SCLC (small-cell lung carcinoma) as compared with healthy tissue (Salgia et al. 1999). Furthermore, paxillin somatic mutations were reported in 9\% of NSCLC (non-small-cell lung cancer); the most frequent of which is the activating mutation A127T, which promoted tumor growth and invasion in a xenograft mouse model (Jagadeeswaran et al. 2008, Mackinnon et al. 2011). Nevertheless, the relevance of paxillin somatic mutations for tumor progression is controversial and other studies found no mutations in lung and other solid tumors (Pallier et al. 2009, Kim et al. 2011). In breast cancer, increased paxillin levels correlate with HER2 overexpression and predict the response to chemotherapy, depending on HER2 status (Short et al. 2007). Paxillin is also involved in conferring aggressive properties to tumor cells. Invadopodia are cellular protrusions involved in ECM degradation and tumor dissemination, and tyrosine phosphorylation of paxillin modulates invadopodia dynamics through ERK-mediated calpain activation (Badowski et al. 2008). Indeed, paxillin phosphorylation at Tyr118 has been shown to control anchorage-independent growth of mouse embryonic fibroblasts (Sachdev et al. 2009). Also, in CRC cell lines and mouse models, paxillin increases survival and chemotherapy resistance in a process involving direct interaction and stabilization of $\mathrm{Bcl} 2$ (Huang et al. 2015). A possible involvement of paxillin in thyroid tumorigenesis has not been addressed.

\section{bArrestins}

bArrestins are cytosolic proteins that mediate homologous desensitization of G-protein-coupled

(c) 2019 Society for Endocrinology Published by Bioscientifica Ltd. Printed in Great Britain receptors (GPCRs) by inducing their internalization (Rajagopal et al. 2010). They have been shown to function as scaffolds for different signaling pathways including ERK, PI3K and NFkB (Dewire et al. 2007). Furthermore, bArrestins can activate ERK indirectly through c-SRC activation and promote the transactivation of TKRs. The Gaq-coupled PAR2 (proteinase-activated receptor-2) receptor is internalized in a process depending on bArrestin and clathrin-coated vesicles, forming protein complexes that include RAF and ERK. In this process, ERK is activated and retained in the cytoplasm and nuclear mitogenic effects of ERK are prevented (Defea et al. 2000). MEK has also been described to be part of this complex and phosphorylates bArrestin2 on Thr383 to recruit and activate ERK upon activation of different GPCRs (Cassier et al. 2017).

bArrestins influence tumor progression by controlling cellular processes such as proliferation, apoptosis, migration, invasion and angiogenesis. In CRC cell lines, PGE2 (prostaglandin E2) induces the formation of a signaling complex containing the PGE receptor 4, bArrestin1 and c-SRC, which leads to transactivation of EGFR. A mutant bArrestin1 with reduced binding to c-SRC was unable to promote EGFR transactivation and decreased cell migration in vitro and liver metastatic disease in vivo (Buchanan et al. 2006). Migration of breast cancer cell lines upon activation of the PAR2 receptor depends on both bArrestin1 and 2-mediated ERK activation (Ge et al. 2004). In NSCLC cell lines, bArrestin 1 translocates to the nucleus in response to nicotine and increases expression of E2F-target genes to promote survival and proliferation (Dasgupta et al. 2011). In contrast to the aforementioned tumor-promoting functions of bArrestins, depletion of bArrestin2 in a mouse lung model increased tumor growth and angiogenesis through NFkB activation (Raghuwanshi et al. 2008). Conversely, decreased expression of bArrestin2 in hepatocellular carcinoma is associated with poor prognosis and aggressive pathological features (Sun et al. 2016). A role for bArrestins in thyroid cancer has not been addressed, although bArrestin1 was reported to be involved in the internationalization of the thyrotropin receptor in rat thyroid-derived cell lines (Frenzel et al. 2006).

\section{MP1/LAMTOR3}

MEK partner 1 (MP1), also known as late endosomal/ lysosomal adaptor MAPK and mTOR activator 3 (LAMTOR3), was first identified in a yeast two-hybrid assay using MEK1 as bait. It was further demonstrated that 
MP1 also binds ERK1 but not MEK2 or ERK2 (Schaeffer et al. 1998). MP1 localizes to the cytoplasmic face of late endosomes through binding to the adaptors p14 (Wunderlich et al. 2001, Teis et al. 2002) and p18 (Nada et al. 2009). In the absence of p14, MP1 is localized in the cytoplasm where it is rapidly targeted for degradation by the proteasome machinery (De Araujo et al. 2013). MP1 also controls activation of the mTORC1 complex at late endosomes/lysosomes (Sancak et al. 2010). Interestingly, MP1 has been shown to bind to other scaffold proteins such as MORG, which is able to bind CRAF, BRAF, MEK1/2 and ERK1/2 and to mediate pathway activation in response to specific extracellular agonists (Vomastek et al. 2004).

MP1 has been associated with the control of FA turnover during migration. Adhesion to fibronectin induces PAK1 (p21-activated kinase) activation of MEK1, in a process mediated by MP1-p14 that ultimately leads to suppression of RHO activity to allow FA turnover and cell spreading (Pullikuth et al. 2005). MP1positive endosomes move along microtubules to the cell periphery to control FA dynamics and migration. Interestingly, MP1 interacts with IQGAP1 and promotes its dissociation from FA, allowing cell migration (Schiefermeier et al. 2014).

Consistent with the actions of MP1-mediating cell adhesion, a pro-tumorigenic role of MP1 has been proposed in different human carcinomas. MP1 mediates migration induced by fibronectin adhesion in prostate cancer cell lines, although, surprisingly, it does not depend on PAK or ERK activation and may rather involve paxillin stabilization at FAs (Park et al. 2009). In addition, MP1 has been implicated in the control of other tumorigenic processes related to tumor survival and resistance mechanisms. In mesenchymal lung cancer cells, MP1-dependent BCL2 expression is associated with acquired chemo-radioresistance and mediates prosurvival signals through AKT1 activation in ER-positive but not ER-negative breast carcinomas (Marina et al. 2012). Furthermore, MP1 expression was associated with poor survival in glioma patients, and was also found to mediate ERK activation downstream of a gain-of-function mutant EGFR, to promote stemness of neural cancer stem cells (Kwon et al. 2017). An opposing role for MP1 has been described in mouse embryonic stem cells, where MP1 depletion impairs FGF4-induced differentiation but not proliferation (Westerman et al. 2011). Finally, in pancreatic carcinomas, overexpression of PAF (PCNAassociated factor) is associated with increased ERK activation and proliferation, and this effect is mediated by PAF-induced MP1 expression (Jun et al. 2013).

\section{IL17RD/SEF}

Interleukin 17 receptor D (IL17RD), also known as similar expression to FGF (SEF), was first identified as an antagonist of fibroblast growth factor (FGF) signaling during zebrafish development (Tsang et al. 2002). SEF functions as a MAPK scaffold, with the ability to bind MEK and ERK mostly at the Golgi apparatus, but also in early endosomes and the plasma membrane. At the Golgi, SEF inhibits MEK-ERK dissociation and blocks ERK nuclear translocation, and therefore, favors the activation of ERK cytosolic substrates in response to different growth factors and in different cell lines (Torii et al. 2004). Upon growth factor stimulation in rat pheochromocytoma PC12 cells, SEF locates at the plasma membrane to interact with EGFR, which increases the stability of the receptor and enhances ERK activation. Interestingly SEF is internalized with the EGFR and is found in early but not late endosomes, thereby favoring recycling versus degradation of the receptor (Torii et al. 2004). SEF has been implicated in the inhibition of other signaling pathways such as PI3K/AKT, downstream of the FGF receptor (FGFR) (Kovalenko et al. 2003) or cytokine signaling through NFkB cytoplasmic retention (Fuchs et al. 2012). Upstream of NFkB, a negative regulation of TLR (toll-like receptor)-induced inflammatory response by SEF has also been described and $1117 \mathrm{rd}^{-/}$mice were found to be more susceptible to septic shock (Mellett et al. 2015). These data indicate that SEF opposes cytokine signaling, acting at different levels, and suggest an important role for SEF in controlling the crosstalk between ERK and inflammatory signaling. An alternatively spliced isoform of SEF, SEF-b, presents a more restricted pattern of expression and impairs ERK but not AKT activation upon FGF or platelet-derived growth factor stimulation (Preger et al. 2004).

Downregulation of SEF expression has been observed in several human carcinomas, including endometrial, breast, ovarian, prostate and thyroid carcinomas (Zisman-Rozen et al. 2007). Interestingly, decreased SEF expression in prostate cancer was particularly frequent in metastatic tissue (Darby et al. 2009) and was shown to increase ERK, p38 and JNK signaling and to promote EMT (Hori et al. 2017). SEF has also been related to the inhibition of EMT in breast cancer, and cytokines that promote EMT also reduce SEF expression (He et al. 2016). SEF expression is decreased in CRC cell lines and human carcinomas compared with normal intestinal epithelial cells and healthy tissue. Expression of oncogenic RAS in normal intestinal epithelial cells abrogates SEF expression and increases MEK/ERK nuclear localization, 
whereas re-expression of SEF in CRC cell lines prevents polyploidization and tumorigenesis (Duhamel et al. 2012).

\section{Phosphoprotein-enriched in astrocytes 15}

Phosphoprotein-enriched in astrocytes 15 (PEA15) was originally identified in a screen for phosphoproteins that could regulate functions in astrocytes (Araujo et al. 1993). Subsequently, PEA15 was found to be widely expressed in most tissues (Danziger et al. 1995). PEA15 binds and retains ERK in the cytoplasm, preventing activation of nuclear but not ERK cytoplasmic effectors (Formstecher et al. 2001). Furthermore, PEA15 binding to ERK also impairs ERK dephosphorylation, providing a pool of activated ERK in the cytoplasm that can elicit a rapid nuclear response upon ERK release from the complex (Mace et al. 2013). The mechanism responsible for maintaining ERK phosphorylation has been explored downstream of FGFR (Haling et al. 2010). FRS2 is an adapter protein that links FGFR to RAS/ERK activation. Activated ERK phosphorylates a threonine residue on FRS2, preventing further activation of the pathway. Binding to PEA15 impairs ERK targeting to the plasma membrane and prevents inactivation of the pathway while blocking entry of ERK to the nucleus. Accordingly, PEA15 increases ERK activation in the cytoplasm. PEA15 can also bind cytoplasmic ERK effectors such as RSK2 but not RSK1, promoting its activation by ERK; this interaction also impairs RSK2 nuclear entry (Vaidyanathan \& Ramos 2003).

Although the mechanisms involved in the disruption of the PEA15/ERK complex are not completely understood, phosphorylation of PEA15 has been proposed as a crucial step. PEA15 presents two phosphorylation sites that are critical for its function: Ser104 - phosphorylated by PKC and Ser116 - phosphorylated by either CaMKII (calcium/ calmodulin-dependent protein kinase II) or AKT (Kubes et al. 1998, Trencia et al. 2003). Phosphorylation of PEA15 at Ser104/116 prevents ERK binding and increases activation of ERK nuclear effectors (Krueger et al. 2005). However, this has been challenged by a report showing that PEA15/ERK-binding affinity does not depend on ERK or PEA15 phosphorylation state (Krueger et al. 2005). The phosphorylation state of PEA15 also modulates the apoptotic role of the protein (Renganathan et al. 2005). PEA15 contains an N-terminal DED (death effector domain) that can be found in proteins involved in apoptotic processes. Through this domain, PEA15 binds FADD (Fas-activated dead domain protein) impairing the recruitment of caspases and the apoptotic cascade.
This binding requires phosphorylation on PEA15 Ser116. This important switch is responsible for the dual action of PEA15 on tumor progression, acting as a pro- or antitumorigenic protein depending on the cellular context. Furthermore, phosphorylation at Ser 116 by AKT increases stability of the protein, implicating PEA15 in the prosurvival actions of AKT (Trencia et al. 2003).

The anti-tumorigenic actions of PEA15 are associated with ERK sequestration at the cytoplasm, whereas protumorigenic actions are related to its anti-apoptotic functions. Altered PEA15 expression has been described in different human carcinomas. PEA15 expression inversely correlates with malignancy grade of astrocytic tumors (Watanabe et al. 2010), and high PEA15 levels are associated with good prognosis in neuroblastoma (Gawecka et al. 2012), CRC (Funke et al. 2013) and ovarian (Bartholomeusz et al. 2008) carcinomas. Expression of PEA15 in cell lines derived from those tumors leads to the inhibition of proliferation, migration, anchorageindependent growth and invasion. By contrast, increased expression of PEA15 has been reported in glioblastoma (Eckert et al. 2008), NSCLC (Zanca et al. 2008) and renal (Heikaus et al. 2008) carcinoma. Importantly, increased PEA15 expression has been found associated with resistance in tumor cells. PEA15 mediates resistance to TRAIL (Zanca et al. 2008) and to glucose (Eckert et al. 2008) and serum (Funke et al. 2013) deprivation in cells derived from different tumor types. In thyroid cancer cell lines, PEA15 is involved in protection from CD95-induced apoptosis through autocrine IL4 and IL10 production, which promotes PEA15 accumulation (Todaro et al. 2006).

\section{Negative regulators and phosphatases}

The balance between positive and negative feedback signals determines the spatiotemporal activation of the ERK pathway and the outcome of a specific input (Marshall 1995). For instance, in PC12 cells, EGF induces proliferation through transient activation of ERK, whereas nerve growth factor promotes neurite outgrowth by activating ERK in a sustained manner (Traverse et al. 1992, Nguyen et al. 1993). In many cases, transient versus sustained activation is a consequence of negative feedback mechanisms. Most negative feedback mechanisms arise from activated ERK that promotes inactivation of the pathway: (i) directly, through phosphorylation of upstream components of the signaling cascade, rendering them inactive; (ii) indirectly, by inducing the expression of protein phosphatases that promote its dephosphorylation or the dephosphorylation (c) 2019 Society for Endocrinology Published by Bioscientifica Ltd. Printed in Great Britain 
of upstream kinases. A summary of the main mechanisms involved in negative regulation of the pathway is depicted in Fig. 7.

\section{Direct negative regulation}

ERK phosphorylates EGFR in a juxtamembrane Thr669 residue. This reduces signaling and trafficking of the receptor due to impaired dimer cross-activation (Li et al. 2008). ERK can also promote the activation of tyrosine phosphatases including CDC25C, which dephosphorylates EGFR at Tyr1068 (Prahallad et al. 2012), a residue required for activation. Interestingly, the poor response to BRAF inhibitors in BRAFV600E CRC-derived cell lines has been explained by the loss of this negative feedback regulatory loop in cells with high levels of EGFR. Other TKRs such as FGFR1 are also negatively regulated by ERK phosphorylation (Zakrzewska et al. 2013). Downstream of the TKRs, ERK phosphorylation of SOS1 on multiple residues impairs its binding to the adaptor proteins $\mathrm{SHC}$ and GRB2, uncoupling from the EGFR and preventing

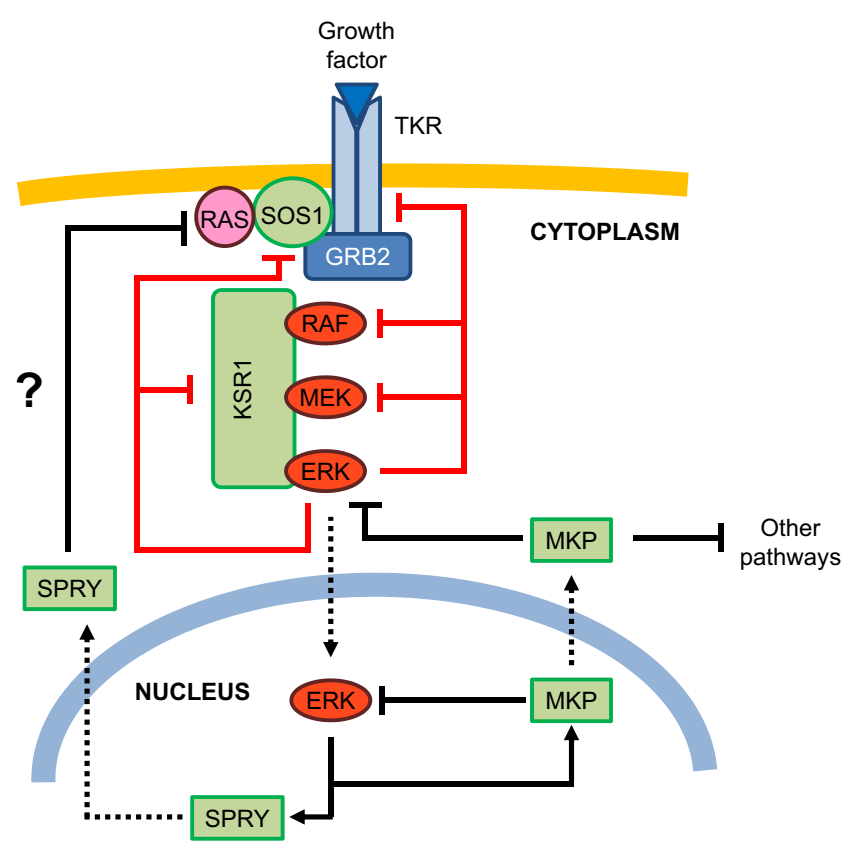

\section{Figure 7}

Negative feedback regulation. Activated ERK elicits a rapid (red lines) and a late (black lines) negative regulatory response. ERK phosphorylates multiple upstream components of the pathway, impairing signaling. Through activation of nuclear ETS transcription factors, ERK induces the expression of MKPs that dephosphorylate ERK in the nucleus and the cytoplasm, and provide points of crosstalk with other signaling pathways. SPRY expression is also induced, inactivating the pathway upstream of ERK in an undefined manner. Arrows indicate activation; blunted lines mean inactivation; dotted lines indicate changes in subcellular localization transmission of the signal (Corbalan-Garcia et al. 1996, Porfiri \& Mccormick 1996, Kamioka et al. 2010). CRAF and BRAF are phosphorylated by ERK at several serine residues, impairing interaction with RAS, membrane localization and dimer formation (Ueki et al. 1994, Wartmann et al. 1997, Dougherty et al. 2005). This particular feedback loop is relevant for BRAFV600E-driven carcinomas, since mutant BRAF does not require dimerization for its activation and is therefore insensitive to this negative feedback loop (Pratilas et al. 2009). The activity of MEK1 and MEK2 is also negatively regulated by ERK1/2 phosphorylation on Thr292 of MEK1. Interestingly the analogous residue is absent in MEK2; nevertheless, phosphorylation of Thr292 on MEK1 also inhibits MEK2 by an undefined mechanism (Catalanotti et al. 2009). Scaffold proteins of the pathway such as KSR1 have also been described to be negatively regulated by multiple phosphorylation events (Cacace et al. 1999), leading to membrane dissociation, disruption of the BRAF-KSR1-MEK1/2 complex and impairment of signal transmission (Mckay et al. 2009).

\section{Indirect negative regulation}

ERK activation also triggers the expression of different negative regulators that elicit inactivation of the pathway in a delayed manner. The best studied are the dualspecificity MAPK phosphatase (MKP) or dual-specificity phosphatase (DUSP) family, which display both threonine and tyrosine phosphatase activity. DUSPs are divided into families according to sequence homology, substrate specificity and subcellular localization. The first group includes the nuclear phosphatases DUSP1, 2 and 4, which dephosphorylate ERK1/2, p38a and JNK (c-Jun N-terminal kinase), and DUSP5, which is specific for ERK1/2. The second group is composed of DUSP6, 7 and 9, which are ERK1/2-specific cytoplasmic phosphatases. The third group comprises the p38a and JNK cytoplasmic and nuclear phosphatases DUSP8, 10 and 16. All DUSPs possess an N-terminal domain (Tanoue et al. 2000) responsible for substrate specificity and subcellular localization and a C-terminal catalytic domain (Keyse \& Ginsburg 1993) that provides phosphatase activity. The mechanism of activation of DUSPs differs among members: DUSP1, 2, 4 and 6 are catalytically activated upon ERK binding (Camps et al. 1998, Chen et al. 2001, Slack et al. 2001, Zhang et al. 2005), whereas DUSP5 and 10 do not require substrate binding for activation (Tanoue et al. 1999, Mandl et al. 2005). Furthermore, DUSP5 can bind and sequester inactive ERK2 at the nucleus (Mandl et al. 2005), whereas DUSP6 can retain inactive ERK2 in the cytoplasm 
(Karlsson et al. 2004), providing a mechanism for ERK signaling compartmentalization.

ERK activation affects MKPs at multiple levels. Expression of DUSP5 and DUSP6 is triggered by growth factor stimulation, depends on MEK activity and is mediated by ETS transcription factors binding to the DUSP5 and 6 promoters (Ekerot et al. 2008, Kucharska et al. 2009). MKPs have a short half-life and are rapidly degraded by the proteasome machinery. DUSP6 is targeted for degradation by the proteasome when phosphorylated by ERK on Ser159 and Ser197 (Marchetti et al. 2005). By contrast, ERK-dependent phosphorylation of Ser359 and Ser364 on DUSP1 and DUSP4 stabilizes the proteins, delaying ubiquitination and degradation (Brondello et al. 1999, Cagnol \& Rivard 2013).

The differences in MKP substrate specificity allow ERK to interact with other signaling pathways. For example, ERK phosphorylation of the JNK phosphatase DUSP16 increases the stability of the protein and enhances the inactivation of the JNK pathway (Katagiri et al. 2005). MKP expression can also be elicited by other signaling cascades, providing points of crosstalk with the MAPK pathways. In lymphocytes and hepatocytes, TGFB (transforming growth factor B) induces the expression of DUSP4 in a SMAD3-dependent manner, impairing ERK-mediated degradation of BIM (Bcl-2-interacting mediator of cell death) and promoting apoptosis (Ramesh et al. 2008). An interesting reciprocal regulation has been described between DUSP6 and FOXO1. FOXO1 is a transcription factor involved in insulin signaling, in which AKT phosphorylation of FOXO1 induces its nuclear export and proteasomal degradation. DUSP6 promotes FOXO1 dephosphorylation, increasing FOXO1 nuclear retention and transcriptional activity (Wu et al. 2010). Interestingly, FOXO1 binds and activates the DUSP6 promoter, increasing the levels of the protein (Feng et al. 2014).

Both DUSP5 and DUSP6 have been found dysregulated in human tumors, suggesting a role for both in tumor progression. DUSP5 expression is lost in gastric and prostate cancer and confers a poor patient outcome. Also ectopic expression of DUSP5 in gastric cancer cell lines reduced proliferation and colony formation in vitro (Shin et al. 2013, Cai et al. 2015). Deletion of DUSP5 in an HRASQ61L-skin carcinogenesis mouse model enhanced the development of skin tumors (Rushworth et al. 2014). These data indicate a tumor suppressor role of DUSP5 in some tumor types.

DUSP6 expression is upregulated in early pancreatic intraepithelial neoplasia, but is downregulated in invasive PDAC (pancreatic ductal adenocarcinoma) due to promoter hypermethylation (Furukawa et al. 2003, 2005, $\mathrm{Xu}$ et al. 2005). A similar situation has been described in KRAS-driven lung tumors where DUSP6 expression is lower in more proliferative and aggressive tumors (Okudela et al. 2009). Interestingly, intrinsic resistance to TRK inhibitors in ELM4/ALK-driven NSCLC has been associated with the loss of DUSP6 expression (Hrustanovic et al. 2015) and prolonged treatment of gastric cancer cell lines with MET (hepatocyte growth factor receptor) inhibitors generates resistance due to loss of DUSP6 expression (Lai et al. 2014). By contrast, DUSP6 expression is increased in human glioblastoma, melanoma and PTC, and DUSP6 overexpression in cell lines derived from those tumors confers increased anchorage-independent growth, migration and invasion (Messina et al. 2011, Li et al. 2012, Degl'Innocenti et al. 2013).

A good example for illustrating the opposing roles of the MKPs in tumor progression is leukemia. Decreased expression of DUSP6 in AML is pro-tumorigenic (Arora et al. 2012), whereas elevated DUSP6 expression is associated with a worst outcome in pre-B ALL (acute B lymphoblastic leukemia) and is necessary for tumor progression. Indeed, pharmacological inhibition of DUSP6 in mice greatly delays the onset of pre-B ALL and is associated with increased ERK activation, reactive oxygen species production and p53-mediated cell death (Shojaee et al. 2015).

In PTC, DUSP5 and DUSP6 are overexpressed in parallel with the degree of activation of the pathway and their silencing in human thyroid tumor cell lines reduces migration, invasion and growth and decreases cell viability depending on the cell line tested (Degl'Innocenti et al. 2013, Buffet et al. 2017). Interestingly, DUSP6 expression is elevated in PDTC but not in ATC (Degl'Innocenti et al. 2013), suggesting that, as in pancreatic and lung carcinomas, expression of MKPs is initially upregulated but then silenced during progression to the most aggressive tumor variants.

MKPs are the most important negative regulators of ERK activation, not only determining the timing of activation of the pathway, but also providing mechanisms of control for ERK-subcellular localization and points of crosstalk with other signaling pathways. Other groups of phosphatases can also dephosphorylate ERK, leading to pathway inactivation (Keyse 2000). A group of phosphatases that catalyzes tyrosine dephosphorylation includes PTP-SL, STEP and HePTP; a second group displays serine/threonine phosphatase activity and includes PP2A and PP2C.

ERK also promotes the expression of the SPRY (Sprouty) family of proteins, which have been implicated 
in the negative regulation of the pathway by an yet unclear mechanism that likely takes place at multiple levels upstream of ERK (Masoumi-Moghaddam et al. 2014). SPRY proteins antagonize ERK activation in response to most growth factors, although EGF-induced ERK phosphorylation is unaffected (Impagnatiello et al. 2001, Sasaki et al. 2001) or even increased (Wong et al. 2002) by SPRY overexpression in cell lines derived from different tissues. Growth factors depending on ERK activation promote the expression of SPRY (Ozaki et al. 2001), though a differential effect on the expression of the different members of the family has also been described in some cell types (Gross et al. 2001, Impagnatiello et al. 2001).

Downregulation of SPRY expression has been described in several human tumors, including breast, prostate, liver or lung carcinomas (Masoumi-Moghaddam et al. 2014). Spry1-knockout mice show thyroid hyperplasia due to impaired NFkB-induced senescence and, when combined with loss of PTEN, show accelerated tumor formation. Unexpectedly, these effects were ERK independent. Decreased SPRY1 expression has also been described in follicular adenomas and FTC (Macia et al. 2014). Furthermore, SPRY1 has been proposed as a tumor suppressor in MTC, where SPRY1 expression is frequently silenced by promoter methylation (Macia et al. 2012).

\section{Concluding remarks}

Spatiotemporal activation of the pivotal RAS-ERK pathway is controlled by GAPs and GEFs that regulate RAS activation, scaffolding proteins that provide subcellular specific localization and optimize signaling and negative regulatory mechanisms involved in the termination of signal transmission. Dysregulation of the expression of the different proteins that participate in ERK signaling dynamics is associated with the progression of human carcinomas and has been shown to frequently mediate resistance to small kinase inhibitors. Despite the essential role that aberrant ERK activation plays in thyroid cancer onset and progression, the functions of these important regulators in the normal physiology of thyroid cells and their alteration in thyroid cancer are largely understudied. Currently, there is a lack of effective treatment options for advanced thyroid carcinomas and the use of small kinase inhibitors of the RAS-ERK pathway has been disappointing, due to the emergence of resistance mechanisms and the toxicity of these systemic treatments. The challenge is to design new therapeutic strategies to overcome these problems. In this respect, mice depleted for Iqgap and $\mathrm{Ksr}$ develop normally; therefore, a high toxicity is not expected for drugs targeting these proteins. This offers the possibility to generate low toxicity approaches that could be used in combination to increase the efficacy of current small kinase inhibitors.

\section{Declaration of interest}

The authors declare that there is no conflict of interest that could be perceived as prejudicing the impartiality of this review.

\section{Funding}

The Santisteban and Crespo Laboratories are supported jointly by grants from Asociación Española Contra el Cancer (AECC; GCB141423113) and CIBERONC from the Instituto de Salud Carlos III (ISCIII). In addition, the authors acknowledge the following funding support: SAF2016-75531-R (MINECO/FEDER, UE); B2017/BMD-3724 Tironet2 (Comunidad de Madrid) and RTICC from ISCIII (RD/12/0036/0030) (granted to P S); and SAF-2015 63638R (MINECO/FEDER, UE) and RTICC (RD/12/0036/0033) (granted to P C).

\section{Acknowledgements}

The authors are grateful to Dr Kenneth McCreath for helpful comments on the manuscript.

\section{References}

Ahmadian MR, Stege P, Scheffzek K \& Wittinghofer A 1997 Confirmation of the arginine-finger hypothesis for the GAPstimulated GTP-hydrolysis reaction of Ras. Nature Structural Biology 4 686-689. (https://doi.org/10.1038/nsb0997-686)

Ahmadian MR, Kiel C, Stege P \& Scheffzek K 2003 Structural fingerprints of the Ras-GTPase activating proteins neurofibromin and p120GAP. Journal of Molecular Biology 329 699-710. (https://doi.org/10.1016/ S0022-2836(03)00514-X)

Allin C, Ahmadian MR, Wittinghofer A \& Gerwert K 2001 Monitoring the GAP catalyzed H-Ras GTPase reaction at atomic resolution in real time. PNAS 98 7754-7759. (https://doi.org/10.1073/pnas.131549798)

Andersen LB, Fountain JW, Gutmann DH, Tarle SA, Glover TW, Dracopoli NC, Housman DE \& Collins FS 1993 Mutations in the neurofibromatosis 1 gene in sporadic malignant melanoma cell lines. Nature Genetics 3 118-121. (https://doi.org/10.1038/ng0293-118)

Araujo H, Danziger N, Cordier J, Glowinski J \& Chneiweiss H 1993 Characterization of PEA-15, a major substrate for protein kinase C in astrocytes. Journal of Biological Chemistry 268 5911-5920.

Arora D, Kothe S, Van Den Eijnden M, Hooft Van Huijsduijnen R, Heidel F, Fischer T, Scholl S, Tolle B, Bohmer SA, Lennartsson J, et al. 2012 Expression of protein-tyrosine phosphatases in Acute myeloid leukemia cells: FLT3 ITD sustains high levels of DUSP6 expression. Cell Communication and Signaling 10 19. (https://doi. org/10.1186/1478-811X-10-19)

Badowski C, Pawlak G, Grichine A, Chabadel A, Oddou C, Jurdic P, Pfaff M, Albiges-Rizo C \& Block MR 2008 Paxillin phosphorylation controls invadopodia/podosomes spatiotemporal organization. Molecular Biology of the Cell 19 633-645. (https://doi.org/10.1091/ mbc.e06-01-0088)

Balenci L, Clarke ID, Dirks PB, Assard N, Ducray F, Jouvet A, Belin MF, Honnorat J \& Baudier J 2006 IQGAP1 protein specifies amplifying (c) 2019 Society for Endocrinology Published by Bioscientifica Ltd. Printed in Great Britain 
cancer cells in glioblastoma multiforme. Cancer Research $6 \mathbf{6}$ 9074-9082. (https://doi.org/10.1158/0008-5472.CAN-06-0761)

Bartholomeusz C, Rosen D, Wei C, Kazansky A, Yamasaki F, Takahashi T, Itamochi H, Kondo S, Liu J \& Ueno NT 2008 PEA-15 induces autophagy in human ovarian cancer cells and is associated with prolonged overall survival. Cancer Research 68 9302-9310. (https:// doi.org/10.1158/0008-5472.CAN-08-2592)

Baschieri F, Confalonieri S, Bertalot G, Di Fiore PP, Dietmaier W, Leist M, Crespo P, Macara IG \& Farhan H 2014 Spatial control of Cdc42 signalling by a GM130-RasGRF complex regulates polarity and tumorigenesis. Nature Communications 5 4839. (https://doi. org/10.1038/ncomms5839)

Bos JL 1988 The ras gene family and human carcinogenesis. Mutation Research 195 255-271. (https://doi.org/10.1016/0165-1110(88)90004-8)

Bos JL, Rehmann H \& Wittinghofer A 2007 GEFs and GAPs: critical elements in the control of small G proteins. Cell 129 865-877. (https://doi.org/10.1016/j.cell.2007.05.018)

Boudry-Labis E, Roche-Lestienne C, Nibourel O, Boissel N, Terre C, Perot C, Eclache V, Gachard N, Tigaud I, Plessis G, et al. 2013 Neurofibromatosis-1 gene deletions and mutations in de novo adult acute myeloid leukemia. American Journal of Hematology 88 306-311. (https://doi.org/10.1002/ajh.23403)

Broek D, Toda T, Michaeli T, Levin L, Birchmeier C, Zoller M, Powers S \& Wigler M 1987 The S. cerevisiae CDC25 gene product regulates the RAS/adenylate cyclase pathway. Cell 48 789-799. (https://doi. org/10.1016/0092-8674(87)90076-6)

Brondello JM, Pouyssegur J \& Mckenzie FR 1999 Reduced MAP kinase phosphatase-1 degradation after p42/p44MAPK-dependent phosphorylation. Science 286 2514-2517. (https://doi.org/10.1126/ science.286.5449.2514)

Buchanan FG, Gorden DL, Matta P, Shi Q, Matrisian LM \& Dubois RN 2006 Role of beta-arrestin 1 in the metastatic progression of colorectal cancer. PNAS 103 1492-1497. (https://doi.org/10.1073/ pnas.0510562103)

Buffet C, Hecale-Perlemoine K, Bricaire L, Dumont F, Baudry C, Tissier F, Bertherat J, Cochand-Priollet B, Raffin-Sanson ML, Cormier F, et al. 2017 DUSP5 and DUSP6, two ERK specific phosphatases, are markers of a higher MAPK signaling activation in BRAF mutated thyroid cancers. PLOS ONE 12 e0184861. (https://doi.org/10.1371/journal. pone.0184861)

Bustelo XR 2018 Rho GTPases in cancer: known facts, open questions, and therapeutic challenges. Biochemical Society Transactions $\mathbf{4 6}$ 741-760. (https://doi.org/10.1042/BST20170531)

Cacace AM, Michaud NR, Therrien M, Mathes K, Copeland T, Rubin GM \& Morrison DK 1999 Identification of constitutive and ras-inducible phosphorylation sites of KSR: implications for 14-3-3 binding, mitogen-activated protein kinase binding, and KSR overexpression. Molecular and Cellular Biology 19 229-240. (https://doi.org/10.1128/ MCB.19.1.229)

Cagnol S \& Rivard N 2013 Oncogenic KRAS and BRAF activation of the MEK/ERK signaling pathway promotes expression of dual-specificity phosphatase 4 (DUSP4/MKP2) resulting in nuclear ERK1/2 inhibition. Oncogene 32 564-576. (https://doi.org/10.1038/ onc.2012.88)

Cai C, Chen JY, Han ZD, He HC, Chen JH, Chen YR, Yang SB, Wu YD, Zeng YR, Zou J, et al. 2015 Down-regulation of dual-specificity phosphatase 5 predicts poor prognosis of patients with prostate cancer. International Journal of Clinical and Experimental Medicine $\mathbf{8}$ 4186-4194.

Calvisi DF, Ladu S, Conner EA, Seo D, Hsieh JT, Factor VM \& Thorgeirsson SS 2011 Inactivation of Ras GTPase-activating proteins promotes unrestrained activity of wild-type Ras in human liver cancer. Journal of Hepatology 54 311-319. (https://doi.org/10.1016/j. jhep.2010.06.036)

Calvo F, Agudo-Ibanez L \& Crespo P 2010 The Ras-ERK pathway: understanding site-specific signaling provides hope of new anti-tumor therapies. BioEssays 32 412-421. (https://doi.org/10.1002/ bies.200900155)

Calvo F, Sanz-Moreno V, Agudo-Ibanez L, Wallberg F, Sahai E, Marshall CJ \& Crespo P 2011 RasGRF suppresses Cdc42-mediated tumour cell movement, cytoskeletal dynamics and transformation. Nature Cell Biology 13 819-826. (https://doi.org/10.1038/ncb2271)

Camps M, Nichols A, Gillieron C, Antonsson B, Muda M, Chabert C, Boschert U \& Arkinstall S 1998 Catalytic activation of the phosphatase MKP-3 by ERK2 mitogen-activated protein kinase. Science 280 1262-1265. (https://doi.org/10.1126/ science.280.5367.1262)

Cancer Genome Atlas Research Network 2014 Integrated genomic characterization of papillary thyroid carcinoma. Cell 159 676-690. (https://doi.org/10.1016/j.cell.2014.09.050)

Carneiro RM, Carneiro BA, Agulnik M, Kopp PA \& Giles FJ 2015 Targeted therapies in advanced differentiated thyroid cancer. Cancer Treatment Reviews 41 690-698. (https://doi.org/10.1016/j. ctrv.2015.06.002)

Cassier E, Gallay N, Bourquard T, Claeysen S, Bockaert J, Crepieux P, Poupon A, Reiter E, Marin P \& Vandermoere F 2017 Phosphorylation of beta-arrestin 2 at $\operatorname{Thr}(383)$ by MEK underlies beta-arrestindependent activation of Erk1/2 by GPCRs. eLife 6 e23777. (https:// doi.org/10.7554/eLife.23777)

Catalanotti F, Reyes G, Jesenberger V, Galabova-Kovacs G, De Matos Simoes R, Carugo O \& Baccarini M 2009 A Mek1-Mek2 heterodimer determines the strength and duration of the Erk signal. Nature Structural and Molecular Biology 16 294-303. (https://doi.org/10.1038/ nsmb.1564)

Chen P, Hutter D, Yang X, Gorospe M, Davis RJ \& Liu Y 2001 Discordance between the binding affinity of mitogen-activated protein kinase subfamily members for MAP kinase phosphatase- 2 and their ability to activate the phosphatase catalytically. Journal of Biological Chemistry 276 29440-29449. (https://doi.org/10.1074/jbc. M103463200)

Chen H, Toyooka S, Gazdar AF \& Hsieh JT 2003 Epigenetic regulation of a novel tumor suppressor gene (hDAB2IP) in prostate cancer cell lines. Journal of Biological Chemistry 278 3121-3130. (https://doi. org/10.1074/jbc.M208230200)

Chen GC, Turano B, Ruest PJ, Hagel M, Settleman J \& Thomas SM 2005 Regulation of Rho and Rac signaling to the actin cytoskeleton by paxillin during Drosophila development. Molecular and Cellular Biology 25 979-987. (https://doi.org/10.1128/МCB.25.3.979987.2005)

Choi KY, Satterberg B, Lyons DM \& Elion EA 1994 Ste5 tethers multiple protein kinases in the MAP kinase cascade required for mating in S. cerevisiae. Cell 78 499-512. (https://doi.org/10.1016/00928674(94)90427-8)

Choi S, Hedman AC, Sayedyahossein S, Thapa N, Sacks DB \& Anderson RA 2016 Agonist-stimulated phosphatidylinositol-3,4,5trisphosphate generation by scaffolded phosphoinositide kinases. Nature Cell Biology 18 1324-1335. (https://doi.org/10.1038/ ncb3441)

Colicelli J 2004 Human RAS superfamily proteins and related GTPases. Science's STKE 2004 RE13. (https://doi.org/10.1126/stke.2502004re13)

Colin I \& Gerard AC 2010 The thyroid angiofollicular units, a biological model of functional and morphological integration. Bulletin et Memoires de l'Academie Royale de Medecine de Belgique 165 218-228; discussion 228-230.

Corbalan-Garcia S, Yang SS, Degenhardt KR \& Bar-Sagi D 1996 Identification of the mitogen-activated protein kinase phosphorylation sites on human Sos1 that regulate interaction with Grb2. Molecular and Cellular Biology 16 5674-5682. (https://doi. org/10.1128/MCB.16.10.5674)

Costanzo-Garvey DL, Pfluger PT, Dougherty MK, Stock JL, Boehm M, Chaika O, Fernandez MR, Fisher K, Kortum RL, Hong EG, et al. 2009 KSR2 is an essential regulator of AMP kinase, energy expenditure, 
and insulin sensitivity. Cell Metabolism 10 366-378. (https://doi. org/10.1016/j.cmet.2009.09.010)

Cox AD, Fesik SW, Kimmelman AC, Luo J \& Der CJ 2014 Drugging the undruggable RAS: mission possible? Nature Reviews: Drug Discovery 13 828-851. (https://doi.org/10.1038/nrd4389)

Dankner M, Rose AAN, Rajkumar S, Siegel PM \& Watson IR 2018 Classifying BRAF alterations in cancer: new rational therapeutic strategies for actionable mutations. Oncogene 37 3183-3199. (https:// doi.org/10.1038/s41388-018-0171-x)

Danziger N, Yokoyama M, Jay T, Cordier J, Glowinski J \& Chneiweiss H 1995 Cellular expression, developmental regulation, and phylogenic conservation of PEA-15, the astrocytic major phosphoprotein and protein kinase C substrate. Journal of Neurochemistry 64 1016-1025. (https://doi.org/10.1046/j.1471-4159.1995.64031016.x)

Darby S, Murphy T, Thomas H, Robson CN, Leung HY, Mathers ME \& Gnanapragasam VJ 2009 Similar expression to FGF (Sef) inhibits fibroblast growth factor-induced tumourigenic behaviour in prostate cancer cells and is downregulated in aggressive clinical disease. British Journal of Cancer 101 1891-1899. (https://doi.org/10.1038/sj. bjc.6605379)

Dasgupta P, Rizwani W, Pillai S, Davis R, Banerjee S, Hug K, Lloyd M, Coppola D, Haura E \& Chellappan SP 2011 ARRB1-mediated regulation of E2F target genes in nicotine-induced growth of lung tumors. Journal of the National Cancer Institute 103 317-333. (https:// doi.org/10.1093/jnci/djq541)

Davies H, Bignell GR, Cox C, Stephens P, Edkins S, Clegg S, Teague J, Woffendin H, Garnett MJ, Bottomley W, et al. 2002 Mutations of the BRAF gene in human cancer. Nature 417 949-954. (https://doi. org/10.1038/nature00766)

De Araujo ME, Stasyk T, Taub N, Ebner HL, Furst B, Filipek P, Weys SR, Hess MW, Lindner H, Kremser L, et al. 2013 Stability of the endosomal scaffold protein LAMTOR3 depends on heterodimer assembly and proteasomal degradation. Journal of Biological Chemistry 288 18228-18242. (https://doi.org/10.1074/jbc.M112.349480)

De Hoog CL, Koehler JA, Goldstein MD, Taylor P, Figeys D \& Moran MF 2001 Ras binding triggers ubiquitination of the Ras exchange factor Ras-GRF2. Molecular and Cellular Biology 21 2107-2117. (https://doi. org/10.1128/MCB.21.6.2107-2117.2001)

Deakin NO \& Turner CE 2008 Paxillin comes of age. Journal of Cell Science 121 2435-2444. (https://doi.org/10.1242/jcs.018044)

Defea KA, Zalevsky J, Thoma MS, Dery O, Mullins RD \& Bunnett NW 2000 Beta-arrestin-dependent endocytosis of proteinase-activated receptor 2 is required for intracellular targeting of activated ERK1/2. Journal of Cell Biology 148 1267-1281. (https://doi.org/10.1083/ jcb.148.6.1267)

Degl'Innocenti D, Romeo P, Tarantino E, Sensi M, Cassinelli G, Catalano V, Lanzi C, Perrone F, Pilotti S, Seregni E, et al. 2013 DUSP6/MKP3 is overexpressed in papillary and poorly differentiated thyroid carcinoma and contributes to neoplastic properties of thyroid cancer cells. Endocrine-Related Cancer 20 23-37. (https://doi. org/10.1530/ERC-12-0078)

Deng Z, Wang L, Hou H, Zhou J \& Li X 2016 Epigenetic regulation of IQGAP2 promotes ovarian cancer progression via activating Wnt/ beta-catenin signaling. International Journal of Oncology 48 153-160. (https://doi.org/10.3892/ijo.2015.3228)

Dever TE, Glynias MJ \& Merrick WC 1987 GTP-binding domain: three consensus sequence elements with distinct spacing. PNAS $\mathbf{8 4}$ 1814-1818. (https://doi.org/10.1073/pnas.84.7.1814)

Dewire SM, Ahn S, Lefkowitz RJ \& Shenoy SK 2007 Beta-arrestins and cell signaling. Annual Review of Physiology 69 483-510. (https://doi. org/10.1146/annurev.ph.69.013107.100021)

Dhawan NS, Scopton AP \& Dar AC 2016 Small molecule stabilization of the KSR inactive state antagonizes oncogenic Ras signalling. Nature 537 112-116. (https://doi.org/10.1038/nature19327)

Ding L, Getz G, Wheeler DA, Mardis ER, Mclellan MD, Cibulskis K, Sougnez C, Greulich H, Muzny DM, Morgan MB, et al. 2008 Somatic mutations affect key pathways in lung adenocarcinoma. Nature $\mathbf{4 5 5}$ 1069-1075. (https://doi.org/10.1038/nature07423)

Dischinger PS, Tovar EA, Essenburg CJ, Madaj ZB, Gardner EE, Callaghan ME, Turner AN, Challa AK, Kempston T, Eagleson B, et al. 2018 NF1 deficiency correlates with estrogen receptor signaling and diminished survival in breast cancer. NPJ Breast Cancer 4 29. (https:// doi.org/10.1038/s41523-018-0080-8)

Dong P, Nabeshima K, Nishimura N, Kawakami T, Hachisuga T, Kawarabayashi T \& Iwasaki H 2006 Overexpression and diffuse expression pattern of IQGAP1 at invasion fronts are independent prognostic parameters in ovarian carcinomas. Cancer Letters $\mathbf{2 4 3}$ 120-127. (https://doi.org/10.1016/j.canlet.2005.11.024)

Dote H, Toyooka S, Tsukuda K, Yano M, Ouchida M, Doihara H, Suzuki M, Chen H, Hsieh JT, Gazdar AF, et al. 2004 Aberrant promoter methylation in human DAB2 interactive protein (hDAB2IP) gene in breast cancer. Clinical Cancer Research 10 2082-2089. (https://doi.org/10.1158/1078-0432.CCR-03-0236)

Dote H, Toyooka S, Tsukuda K, Yano M, Ota T, Murakami M, Naito M, Toyota M, Gazdar AF \& Shimizu N 2005 Aberrant promoter methylation in human DAB2 interactive protein (hDAB2IP) gene in gastrointestinal tumour. British Journal of Cancer 92 1117-1125. (https://doi.org/10.1038/sj.bjc.6602458)

Dougherty MK, Muller J, Ritt DA, Zhou M, Zhou XZ, Copeland TD, Conrads TP, Veenstra TD, Lu KP \& Morrison DK 2005 Regulation of Raf-1 by direct feedback phosphorylation. Molecular Cell 17 215-224. (https://doi.org/10.1016/j.molcel.2004.11.055)

Duhamel S, Hebert J, Gaboury L, Bouchard A, Simon R, Sauter G, Basik M \& Meloche S 2012 Sef downregulation by Ras causes MEK1/2 to become aberrantly nuclear localized leading to polyploidy and neoplastic transformation. Cancer Research $\mathbf{7 2}$ 626-635. (https://doi.org/10.1158/0008-5472.CAN-11-2126)

Eckert A, Bock BC, Tagscherer KE, Haas TL, Grund K, Sykora J, HeroldMende C, Ehemann V, Hollstein M, Chneiweiss H, et al. 2008 The PEA-15/PED protein protects glioblastoma cells from glucose deprivation-induced apoptosis via the ERK/MAP kinase pathway. Oncogene 27 1155-1166. (https://doi.org/10.1038/sj.onc.1210732)

Ekerot M, Stavridis MP, Delavaine L, Mitchell MP, Staples C, Owens DM, Keenan ID, Dickinson RJ, Storey KG \& Keyse SM 2008 Negativefeedback regulation of FGF signalling by DUSP6/MKP-3 is driven by ERK1/2 and mediated by Ets factor binding to a conserved site within the DUSP6/MKP-3 gene promoter. Biochemical Journal $\mathbf{4 1 2}$ 287-298. (https://doi.org/10.1042/BJ20071512)

Feng B, He Q \& Xu H 2014 FOXO1-dependent up-regulation of MAP kinase phosphatase 3 (MKP-3) mediates glucocorticoid-induced hepatic lipid accumulation in mice. Molecular and Cellular Endocrinology 393 46-55. (https://doi.org/10.1016/j.mce.2014.06.001)

Fernandez MR, Henry MD \& Lewis RE 2012 Kinase suppressor of ras 2 (KSR2) regulates tumor cell transformation via AMPK. Molecular and Cellular Biology 32 3718-3731. (https://doi.org/10.1128/МСB.06754-11)

Fernandez-Medarde A \& Santos E 2011 The RasGrf family of mammalian guanine nucleotide exchange factors. Biochimica and Biophysica Acta 1815 170-188. (https://doi.org/10.1016/j.bbcan.2010.11.001)

Fiegen D, Dvorsky R \& Ahmadian MR 2006 Structural principles of Ras interaction with regulators and effectors. In RAS Family GTPases. Proteins and Cell Regulation. Ed. C Der, vol 4. Dordrecht, Netherlands: Springer. (https://doi.org/10.1007/1-4020-4708-8_3)

Formstecher E, Ramos JW, Fauquet M, Calderwood DA, Hsieh JC, Canton B, Nguyen XT, Barnier JV, Camonis J, Ginsberg MH, et al. 2001 PEA-15 mediates cytoplasmic sequestration of ERK MAP kinase. Developmental Cell 1 239-250. (https://doi.org/10.1016/S15345807(01)00035-1)

Frenzel R, Voigt C \& Paschke R 2006 The human thyrotropin receptor is predominantly internalized by beta-arrestin 2. Endocrinology 147 3114-3122. (https://doi.org/10.1210/en.2005-0687)

Friedman E, Gejman PV, Martin GA \& Mccormick F 1993 Nonsense mutations in the C-terminal SH2 region of the GTPase activating (c) 2019 Society for Endocrinology Published by Bioscientifica Ltd. Printed in Great Britain 
protein (GAP) gene in human tumours. Nature Genetics 5 242-247. (https://doi.org/10.1038/ng1193-242)

Frodyma D, Neilsen B, Costanzo-Garvey D, Fisher K \& Lewis R 2017 Coordinating ERK signaling via the molecular scaffold kinase suppressor of ras. F1000Research 6 1621. (https://doi.org/10.12688/ f1000research.11895.1)

Fuchs Y, Brunwasser M, Haif S, Haddad J, Shneyer B, GoldshmidtTran O, Korsensky L, Abed M, Zisman-Rozen S, Koren L, et al. 2012 Sef is an inhibitor of proinflammatory cytokine signaling, acting by cytoplasmic sequestration of NF-kappaB. Developmental Cell 23 611-623. (https://doi.org/10.1016/j.devcel.2012.07.013)

Funke V, Lehmann-Koch J, Bickeboller M, Benner A, Tagscherer KE, Grund K, Pfeifer M, Herpel E, Schirmacher P, Chang-Claude J, et al. 2013 The PEA-15/PED protein regulates cellular survival and invasiveness in colorectal carcinomas. Cancer Letters 335 431-440. (https://doi.org/10.1016/j.canlet.2013.02.053)

Furukawa T, Sunamura M, Motoi F, Matsuno S \& Horii A 2003 Potential tumor suppressive pathway involving DUSP6/MKP-3 in pancreatic cancer. American Journal of Pathology 162 1807-1815. (https://doi. org/10.1016/S0002-9440(10)64315-5)

Furukawa T, Fujisaki R, Yoshida Y, Kanai N, Sunamura M, Abe T, Takeda K, Matsuno S \& Horii A 2005 Distinct progression pathways involving the dysfunction of DUSP6/MKP-3 in pancreatic intraepithelial neoplasia and intraductal papillary-mucinous neoplasms of the pancreas. Modern Pathology 18 1034-1042. (https:// doi.org/10.1038/modpathol.3800383)

Garcia-Gomez R, Bustelo XR \& Crespo P 2018 Protein-protein interactions: emerging oncotargets in the RAS-ERK pathway. Trends in Cancer 4 616-633. (https://doi.org/10.1016/j.trecan.2018.07.002)

Garcia-Rendueles ME, Ricarte-Filho JC, Untch BR, Landa I, Knauf JA, Voza F, Smith VE, Ganly I, Taylor BS, Persaud Y, et al. 2015 NF2 loss promotes oncogenic RAS-induced thyroid cancers via YAP-dependent transactivation of RAS proteins and sensitizes them to MEK inhibition. Cancer Discovery 5 1178-1193. (https://doi. org/10.1158/2159-8290.CD-15-0330)

Gawecka JE, Geerts D, Koster J, Caliva MJ, Sulzmaier FJ, Opoku-Ansah J, Wada RK, Bachmann AS \& Ramos JW 2012 PEA15 impairs cell migration and correlates with clinical features predicting good prognosis in neuroblastoma. International Journal of Cancer 131 1556-1568. (https://doi.org/10.1002/ijc.27415)

Ge L, Shenoy SK, Lefkowitz RJ \& Defea K 2004 Constitutive proteaseactivated receptor-2-mediated migration of MDA MB-231 breast cancer cells requires both beta-arrestin-1 and -2. Journal of Biological Chemistry 279 55419-55424. (https://doi.org/10.1074/jbc. M410312200)

Glenney JR, Jr \& Zokas L 1989 Novel tyrosine kinase substrates from Rous sarcoma virus-transformed cells are present in the membrane skeleton. Journal of Cell Biology 108 2401-2408. (https://doi. org/10.1083/jcb.108.6.2401)

Gross I, Bassit B, Benezra M \& Licht JD 2001 Mammalian sprouty proteins inhibit cell growth and differentiation by preventing ras activation. Journal of Biological Chemistry 276 46460-46468. (https:// doi.org/10.1074/jbc.M108234200)

Haling JR, Wang F \& Ginsberg MH 2010 Phosphoprotein enriched in astrocytes $15 \mathrm{kDa}$ (PEA-15) reprograms growth factor signaling by inhibiting threonine phosphorylation of fibroblast receptor substrate 2alpha. Molecular Biology of the Cell 21 664-673. (https://doi. org/10.1091/mbc.e09-08-0659)

Hall BE, Bar-Sagi D \& Nassar N 2002 The structural basis for the transition from Ras-GTP to Ras-GDP. PNAS 99 12138-12142. (https:// doi.org/10.1073/pnas.192453199)

Hart TC, Zhang Y, Gorry MC, Hart PS, Cooper M, Marazita ML, Marks JM, Cortelli JR \& Pallos D 2002 A mutation in the SOS1 gene causes hereditary gingival fibromatosis type 1. American Journal of Human Genetics 70 943-954. (https://doi.org/10.1086/339689)
Hay ID, Thompson GB, Grant CS, Bergstralh EJ, Dvorak CE, Gorman CA, Maurer MS, Mciver B, Mullan BP, Oberg AL, et al. 2002 Papillary thyroid carcinoma managed at the Mayo Clinic during six decades (1940-1999): temporal trends in initial therapy and longterm outcome in 2444 consecutively treated patients. World Journal of Surgery 26 879-885. (https://doi.org/10.1007/s00268-002-6612-1)

He Q, Gong Y, Gower L, Yang X \& Friesel RE 2016 Sef regulates epithelial-mesenchymal transition in breast cancer cells. Journal of Cellular Biochemistry 117 2346-2356. (https://doi.org/10.1002/ jcb.25532)

Hedman AC, Smith JM \& Sacks DB 2015 The biology of IQGAP proteins: beyond the cytoskeleton. EMBO Reports 16 427-446. (https://doi. org/10.15252/embr.201439834)

Heikaus S, Kempf T, Mahotka C, Gabbert HE \& Ramp U 2008 Caspase-8 and its inhibitors in RCCs in vivo: the prominent role of ARC. Apoptosis 13 938-949. (https://doi.org/10.1007/s10495-008-0225-6)

Henkemeyer M, Rossi DJ, Holmyard DP, Puri MC, Mbamalu G, Harpal K, Shih TS, Jacks T \& Pawson T 1995 Vascular system defects and neuronal apoptosis in mice lacking ras GTPase-activating protein. Nature 377 695-701. (https://doi.org/10.1038/377695a0)

Herrero A, Pinto A, Colon-Bolea P, Casar B, Jones M, Agudo-Ibanez L, Vidal R, Tenbaum SP, Nuciforo P, Valdizan EM, et al. 2015 Small molecule inhibition of ERK dimerization prevents tumorigenesis by RAS-ERK pathway oncogenes. Cancer Cell 28 170-182. (https://doi. org/10.1016/j.ccell.2015.07.001)

Hori S, Wadhwa K, Pisupati V, Zecchini V, Ramos-Montoya A, Warren AY, Neal DE \& Gnanapragasam VJ 2017 Loss of hSef promotes metastasis through upregulation of EMT in prostate cancer. International Journal of Cancer 140 1881-1887. (https://doi. org/10.1002/ijc.30604)

Horn S, Figl A, Rachakonda PS, Fischer C, Sucker A, Gast A, Kadel S, Moll I, Nagore E, Hemminki K, et al. 2013 Tert promoter mutations in familial and sporadic melanoma. Science 339 959-961. (https:// doi.org/10.1126/science.1230062)

Hrustanovic G, Olivas V, Pazarentzos E, Tulpule A, Asthana S, Blakely CM, Okimoto RA, Lin L, Neel DS, Sabnis A, et al. 2015 RASMAPK dependence underlies a rational polytherapy strategy in EML4-ALK-positive lung cancer. Nature Medicine 21 1038-1047. (https://doi.org/10.1038/nm.3930)

Huang FW, Hodis E, Xu MJ, Kryukov GV, Chin L \& Garraway LA 2013 Highly recurrent tert promoter mutations in human melanoma. Science 339 957-959. (https://doi.org/10.1126/science.1229259)

Huang CC, Wu DW, Lin PL \& Lee H 2015 Paxillin promotes colorectal tumor invasion and poor patient outcomes via ERK-mediated stabilization of Bcl-2 protein by phosphorylation at serine 87 . Oncotarget 6 8698-8708. (https://doi.org/10.18632/oncotarget.3537)

Huser M, Luckett J, Chiloeches A, Mercer K, Iwobi M, Giblett S, Sun XM, Brown J, Marais R \& Pritchard C 2001 MEK kinase activity is not necessary for Raf-1 function. EMBO Journal 20 1940-1951. (https://doi.org/10.1093/emboj/20.8.1940)

Impagnatiello MA, Weitzer S, Gannon G, Compagni A, Cotten M \& Christofori G 2001 Mammalian sprouty-1 and -2 are membraneanchored phosphoprotein inhibitors of growth factor signaling in endothelial cells. Journal of Cell Biology 152 1087-1098. (https://doi org $/ 10.1083 /$ jcb.152.5.1087)

Ishibe S, Joly D, Zhu X \& Cantley LG 2003 Phosphorylation-dependent paxillin-ERK association mediates hepatocyte growth factorstimulated epithelial morphogenesis. Molecular Cell 12 1275-1285. (https://doi.org/10.1016/S1097-2765(03)00406-4)

Ishibe S, Joly D, Liu ZX \& Cantley LG 2004 Paxillin serves as an ERKregulated scaffold for coordinating FAK and Rac activation in epithelial morphogenesis. Molecular Cell 16 257-267. (https://doi. org/10.1016/j.molcel.2004.10.006)

Jadeski L, Mataraza JM, Jeong HW, Li Z \& Sacks DB 2008 IQGAP1 stimulates proliferation and enhances tumorigenesis of human https://erc.bioscientifica.com

https://doi.org/10.1530/ERC-19-0098
C) 2019 Society for Endocrinology Published by Bioscientifica Ltd. Printed in Great Britain 
breast epithelial cells. Journal of Biological Chemistry 283 1008-1017. (https://doi.org/10.1074/jbc.M708466200)

Jagadeeswaran R, Surawska H, Krishnaswamy S, Janamanchi V, Mackinnon AC, Seiwert TY, Loganathan S, Kanteti R, Reichman T, Nallasura V, et al. 2008 Paxillin is a target for somatic mutations in lung cancer: implications for cell growth and invasion. Cancer Research 68 132-142. (https://doi.org/10.1158/0008-5472.CAN-071998)

Jameson KL, Mazur PK, Zehnder AM, Zhang J, Zarnegar B, Sage J \& Khavari PA 2013 IQGAP1 scaffold-kinase interaction blockade selectively targets RAS-MAP kinase-driven tumors. Nature Medicine 19 626-630. (https://doi.org/10.1038/nm.3165)

Jin SH, Akiyama Y, Fukamachi H, Yanagihara K, Akashi T \& Yuasa Y 2008 IQGAP2 inactivation through aberrant promoter methylation and promotion of invasion in gastric cancer cells. International Journal of Cancer 122 1040-1046. (https://doi.org/10.1002/ijc.23181)

Jun S, Lee S, Kim HC, Ng C, Schneider AM, Ji H, Ying H, Wang H, Depinho RA \& Park JI 2013 PAF-mediated MAPK signaling hyperactivation via LAMTOR3 induces pancreatic tumorigenesis. Cell Reports 5 314-322. (https://doi.org/10.1016/j.celrep.2013.09.026)

Kamioka Y, Yasuda S, Fujita Y, Aoki K \& Matsuda M 2010 Multiple decisive phosphorylation sites for the negative feedback regulation of SOS1 via ERK. Journal of Biological Chemistry 285 33540-33548. (https://doi.org/10.1074/jbc.M110.135517)

Karlsson M, Mathers J, Dickinson RJ, Mandl M \& Keyse SM 2004 Both nuclear-cytoplasmic shuttling of the dual specificity phosphatase MKP-3 and its ability to anchor MAP kinase in the cytoplasm are mediated by a conserved nuclear export signal. Journal of Biological Chemistry 279 41882-41891. (https://doi.org/10.1074/jbc. M406720200)

Katagiri C, Masuda K, Urano T, Yamashita K, Araki Y, Kikuchi K \& Shima H 2005 Phosphorylation of Ser-446 determines stability of MKP-7. Journal of Biological Chemistry 280 14716-14722. (https://doi. org/10.1074/jbc.M500200200)

Keyse SM 2000 Protein phosphatases and the regulation of mitogenactivated protein kinase signalling. Current Opinion in Cell Biology 12 186-192. (https://doi.org/10.1016/S0955-0674(99)00075-7)

Keyse SM \& Ginsburg M 1993 Amino acid sequence similarity between CL100, a dual-specificity MAP kinase phosphatase and cdc25. Trends in Biochemical Sciences 18 377-378. (https://doi.org/10.1016/09680004(93)90092-2)

Kim M, Yan Y, Kortum RL, Stoeger SM, Sgagias MK, Lee K, Lewis RE \& Cowan KH 2005 Expression of kinase suppressor of Ras1 enhances cisplatin-induced extracellular signal-regulated kinase activation and cisplatin sensitivity. Cancer Research 65 3986-3992. (https://doi. org/10.1158/0008-5472.CAN-03-2334)

Kim MS, Yoo NJ \& Lee SH 2011 Absence of paxillin gene mutation in lung cancer and other common solid cancers. Tumori 97 211-213. (https://doi.org/10.1700/667.7785)

Koehler JA \& Moran MF 2001 RACK1, a protein kinase C scaffolding protein, interacts with the PH domain of p120GAP. Biochemical and Biophysical Research Communications 283 888-895. (https://doi. org/10.1006/bbrc.2001.4889)

Kornfeld K, Hom DB \& Horvitz HR 1995 The ksr-1 gene encodes a novel protein kinase involved in Ras-mediated signaling in C. elegans. Cell 83 903-913. (https://doi.org/10.1016/0092-8674(95)90206-6)

Kovalenko D, Yang X, Nadeau RJ, Harkins LK \& Friesel R 2003 Sef inhibits fibroblast growth factor signaling by inhibiting FGFR1 tyrosine phosphorylation and subsequent ERK activation. Journal of Biological Chemistry 278 14087-14091. (https://doi.org/10.1074/jbc. C200606200)

Krauthammer M, Kong Y, Bacchiocchi A, Evans P, Pornputtapong N, Wu C, Mccusker JP, Ma S, Cheng E, Straub R, et al. 2015 Exome sequencing identifies recurrent mutations in NF1 and RASopathy genes in sun-exposed melanomas. Nature Genetics 47 996-1002. (https://doi.org/10.1038/ng.3361)
Krishnamoorthy GP, Davidson NR, Leach SD, Zhao Z, Lowe SW, Lee G, Landa I, Nagarajah J, Saqcena M, Singh K, et al. 2019 EIF1AX and RAS mutations cooperate to drive thyroid tumorigenesis through ATF4 and c-MYC. Cancer Discovery 9 264-281. (https://doi. org/10.1158/2159-8290.CD-18-0606)

Kroll TG, Sarraf P, Pecciarini L, Chen CJ, Mueller E, Spiegelman BM \& Fletcher JA 2000 PAX8-PPARgamma1 fusion oncogene in human thyroid carcinoma. Science 289 1357-1360. (https://doi.org/10.1126/ science.289.5483.1357)

Krueger J, Chou FL, Glading A, Schaefer E \& Ginsberg MH 2005 Phosphorylation of phosphoprotein enriched in astrocytes (PEA-15) regulates extracellular signal-regulated kinase-dependent transcription and cell proliferation. Molecular Biology of the Cell 16 3552-3561. (https://doi.org/10.1091/mbc.e04-11-1007)

Ksionda O, Limnander A \& Roose JP 2013 RasGRP Ras guanine nucleotide exchange factors in cancer. Frontiers in Biology 8 508-532. (https://doi.org/10.1007/s11515-013-1276-9)

Kubes M, Cordier J, Glowinski J, Girault JA \& Chneiweiss H 1998 Endothelin induces a calcium-dependent phosphorylation of PEA-15 in intact astrocytes: identification of Ser104 and Ser116 phosphorylated, respectively, by protein kinase C and calcium/ calmodulin kinase II in vitro. Journal of Neurochemistry $\mathbf{7 1}$ 1307-1314. (https://doi.org/10.1046/j.1471-4159.1998.71031307.x)

Kucharska A, Rushworth LK, Staples C, Morrice NA \& Keyse SM 2009 Regulation of the inducible nuclear dual-specificity phosphatase DUSP5 by ERK MAPK. Cellular Signalling 21 1794-1805. (https://doi. org/10.1016/j.cellsig.2009.07.015)

Kumar D, Hassan MK, Pattnaik N, Mohapatra N \& Dixit M 2017 Reduced expression of IQGAP2 and higher expression of IQGAP3 correlates with poor prognosis in cancers. PLOS ONE 12 e0186977. (https://doi.org/10.1371/journal.pone.0186977)

Kunstman JW, Juhlin CC, Goh G, Brown TC, Stenman A, Healy JM, Rubinstein JC, Choi M, Kiss N, Nelson-Williams C, et al. 2015 Characterization of the mutational landscape of anaplastic thyroid cancer via whole-exome sequencing. Human Molecular Genetics $\mathbf{2 4}$ 2318-2329. (https://doi.org/10.1093/hmg/ddu749)

Kwon SJ, Kwon OS, Kim KT, Go YH, Yu SI, Lee BH, Miyoshi H, Oh E, Cho SJ \& Cha HJ 2017 Role of MEK partner-1 in cancer stemness through MEK/ERK pathway in cancerous neural stem cells, expressing EGFRviii. Molecular Cancer 16 140. (https://doi. org/10.1186/s12943-017-0703-y)

Kyriakis JM, App H, Zhang XF, Banerjee P, Brautigan DL, Rapp UR \& Avruch J 1992 Raf-1 activates MAP kinase-kinase. Nature 358 417-421. (https://doi.org/10.1038/358417a0)

Lai AZ, Cory S, Zhao H, Gigoux M, Monast A, Guiot MC, Huang S, Tofigh A, Thompson C, Naujokas M, et al. 2014 Dynamic reprogramming of signaling upon met inhibition reveals a mechanism of drug resistance in gastric cancer. Science Signaling $\mathbf{7}$ ra38. (https://doi.org/10.1126/scisignal.2004839)

Landa I, Ibrahimpasic T, Boucai L, Sinha R, Knauf JA, Shah RH, Dogan S, Ricarte-Filho JC, Krishnamoorthy GP, Xu B, et al. 2016 Genomic and transcriptomic hallmarks of poorly differentiated and anaplastic thyroid cancers. Journal of Clinical Investigation 126 1052-1066. (https://doi.org/10.1172/JCI85271)

Lavoie H \& Therrien M 2015 Regulation of RAF protein kinases in ERK signalling. Nature Reviews: Molecular Cell Biology 16 281-298. (https:// doi.org/10.1038/nrm3979)

Lavoie H, Sahmi M, Maisonneuve P, Marullo SA, Thevakumaran N, Jin T, Kurinov I, Sicheri F \& Therrien M 2018 MEK drives BRAF activation through allosteric control of KSR proteins. Nature 554 549-553. (https://doi.org/10.1038/nature25478)

Lee J, Seol MY, Jeong S, Kwon HJ, Lee CR, Ku CR, Kang SW, Jeong JJ, Shin DY, Nam KH, et al. 2015 KSR1 is coordinately regulated with Notch signaling and oxidative phosphorylation in thyroid cancer. Journal of Molecular Endocrinology 54 115-124. (https://doi. org/10.1530/JME-14-0270) https://erc.bioscientifica.com

https://doi.org/10.1530/ERC-19-0098 (c) 2019 Society for Endocrinology Published by Bioscientifica Ltd. Printed in Great Britain 
Li S, Wang Q, Chakladar A, Bronson RT \& Bernards A 2000 Gastric hyperplasia in mice lacking the putative Cdc42 effector IQGAP1. Molecular and Cellular Biology 20 697-701. (https://doi.org/10.1128/ MCB.20.2.697-701.2000)

Li X, Huang Y, Jiang J \& Frank SJ 2008 ERK-dependent threonine phosphorylation of EGF receptor modulates receptor downregulation and signaling. Cellular Signalling 20 2145-2155. (https://doi. org/10.1016/j.cellsig.2008.08.006)

Li W, Song L, Ritchie AM \& Melton DW 2012 Increased levels of DUSP6 phosphatase stimulate tumourigenesis in a molecularly distinct melanoma subtype. Pigment Cell and Melanoma Research 25 188-199. (https://doi.org/10.1111/j.1755-148X.2011.00949.x)

Lim H, Devesa SS, Sosa JA, Check D \& Kitahara CM 2017 Trends in thyroid cancer incidence and mortality in the United States, 19742013. JAMA 317 1338-1348. (https://doi.org/10.1001/ jama.2017.2719)

Liu Z, Liu D, Bojdani E, El-Naggar AK, Vasko V \& Xing M 2010 IQGAP1 plays an important role in the invasiveness of thyroid cancer. Clinical Cancer Research 16 6009-6018. (https://doi. org/10.1158/1078-0432.CCR-10-1627)

Liu H, Li Z, Li L, Peng H \& Zhang Z 2015 EBP1 suppresses growth, migration, and invasion of thyroid cancer cells through upregulating RASAL expression. Tumour Biology 36 8325-8331. (https://doi. org/10.1007/s13277-015-3523-y)

Liu R, Zhang T, Zhu G \& Xing M 2018 Regulation of mutant tert by BRAF V600E/MAP kinase pathway through FOS/GABP in human cancer. Nature Communications 9 579. (https://doi.org/10.1038/ s41467-018-03033-1)

Lozano J, Xing R, Cai Z, Jensen HL, Trempus C, Mark W, Cannon R \& Kolesnick R 2003 Deficiency of kinase suppressor of Ras1 prevents oncogenic ras signaling in mice. Cancer Research 63 4232-4238.

Lu P, Chen J, Yan L, Yang L, Zhang L, Dai J, Hao Z, Bai T, Xi Y, Li Y, et al. 2018 RasGRF2 promotes migration and invasion of colorectal cancer cells by modulating expression of MMP9 through Src/Akt/ NF-kappaB pathway. Cancer Biology and Therapy 20 435-443. (https://doi.org/10.1080/15384047.2018.1529117)

Mace PD, Wallez Y, Egger MF, Dobaczewska MK, Robinson H, Pasquale EB \& Riedl SJ 2013 Structure of ERK2 bound to PEA-15 reveals a mechanism for rapid release of activated MAPK. Nature Communications 4 1681. (https://doi.org/10.1038/ncomms2687)

Macia A, Gallel P, Vaquero M, Gou-Fabregas M, Santacana M, Maliszewska A, Robledo M, Gardiner JR, Basson MA, Matias-Guiu X, et al. 2012 Sprouty1 is a candidate tumor-suppressor gene in medullary thyroid carcinoma. Oncogene 31 3961-3972. (https://doi. org/10.1038/onc.2011.556)

Macia A, Vaquero M, Gou-Fabregas M, Castelblanco E, Valdivielso JM, Anerillas C, Mauricio D, Matias-Guiu X, Ribera J \& Encinas M 2014 Sprouty1 induces a senescence-associated secretory phenotype by regulating NFkappaB activity: implications for tumorigenesis. Cell Death and Differentiation 21 333-343. (https://doi.org/10.1038/ cdd.2013.161)

Mackinnon AC, Tretiakova M, Henderson L, Mehta RG, Yan BC, Joseph L, Krausz T, Husain AN, Reid ME \& Salgia R 2011 Paxillin expression and amplification in early lung lesions of high-risk patients, lung adenocarcinoma and metastatic disease. Journal of Clinical Pathology 64 16-24. (https://doi.org/10.1136/ jcp.2010.075853)

Mandal R, Becker S \& Strebhardt K 2016 Stamping out RAF and MEK1/2 to inhibit the ERK1/2 pathway: an emerging threat to anticancer therapy. Oncogene 35 2547-2561. (https://doi.org/10.1038/ onc.2015.329)

Mandl M, Slack DN \& Keyse SM 2005 Specific inactivation and nuclear anchoring of extracellular signal-regulated kinase 2 by the inducible dual-specificity protein phosphatase DUSP5. Molecular and Cellular Biology 25 1830-1845. (https://doi.org/10.1128/MCB.25.5.18301845.2005)
Marchetti S, Gimond C, Chambard JC, Touboul T, Roux D, Pouyssegur J \& Pages G 2005 Extracellular signal-regulated kinases phosphorylate mitogen-activated protein kinase phosphatase 3/DUSP6 at serines 159 and 197, two sites critical for its proteasomal degradation. Molecular and Cellular Biology 25 854-864. (https://doi.org/10.1128/ MCB.25.2.854-864.2005)

Marina M, Wang L \& Conrad SE 2012 The scaffold protein MEK partner 1 is required for the survival of estrogen receptor positive breast cancer cells. Cell Communication and Signaling 10 18. (https://doi. org/10.1186/1478-811X-10-18)

Marshall CJ 1995 Specificity of receptor tyrosine kinase signaling: transient versus sustained extracellular signal-regulated kinase activation. Cell 80 179-185. (https://doi.org/10.1016/00928674(95)90401-8)

Mason CS, Springer CJ, Cooper RG, Superti-Furga G, Marshall CJ \& Marais R 1999 Serine and tyrosine phosphorylations cooperate in Raf-1, but not B-Raf activation. EMBO Journal 18 2137-2148. (https://doi.org/10.1093/emboj/18.8.2137)

Masoumi-Moghaddam S, Amini A \& Morris DL 2014 The developing story of Sprouty and cancer. Cancer Metastasis Reviews 33 695-720. (https://doi.org/10.1007/s10555-014-9497-1)

Matheny SA, Chen C, Kortum RL, Razidlo GL, Lewis RE \& White MA 2004 Ras regulates assembly of mitogenic signalling complexes through the effector protein IMP. Nature 427 256-260. (https://doi. org/10.1038/nature02237)

Mckay MM, Ritt DA \& Morrison DK 2009 Signaling dynamics of the KSR1 scaffold complex. PNAS 106 11022-11027. (https://doi. org/10.1073/pnas.0901590106)

Mckay MM, Ritt DA \& Morrison DK 2011 RAF inhibitor-induced KSR1/ B-RAF binding and its effects on ERK cascade signaling. Current Biology 21 563-568. (https://doi.org/10.1016/j.cub.2011.02.033)

Mellett M, Atzei P, Bergin R, Horgan A, Floss T, Wurst W, Callanan JJ \& Moynagh PN 2015 Orphan receptor IL-17RD regulates Toll-like receptor signalling via SEFIR/TIR interactions. Nature Communications 6 6669. (https://doi.org/10.1038/ncomms7669)

Messina S, Frati L, Leonetti C, Zuchegna C, Di Zazzo E, Calogero A \& Porcellini A 2011 Dual-specificity phosphatase DUSP6 has tumorpromoting properties in human glioblastomas. Oncogene $\mathbf{3 0}$ 3813-3820. (https://doi.org/10.1038/onc.2011.99)

Mikula M, Schreiber M, Husak Z, Kucerova L, Ruth J, Wieser R, Zatloukal K, Beug H, Wagner EF \& Baccarini M 2001 Embryonic lethality and fetal liver apoptosis in mice lacking the c-raf-1 gene. EMBO Journal 20 1952-1962. (https://doi.org/10.1093/ emboj/20.8.1952)

Muller J, Ory S, Copeland T, Piwnica-Worms H \& Morrison DK 2001 C-TAK1 regulates Ras signaling by phosphorylating the MAPK scaffold, KSR1. Molecular Cell 8 983-993. (https://doi.org/10.1016/ S1097-2765(01)00383-5)

Nada S, Hondo A, Kasai A, Koike M, Saito K, Uchiyama Y \& Okada M 2009 The novel lipid raft adaptor p18 controls endosome dynamics by anchoring the MEK-ERK pathway to late endosomes. EMBO Journal 28 477-489. (https://doi.org/10.1038/emboj.2008.308)

Nagarajah J, Le M, Knauf JA, Ferrandino G, Montero-Conde C, Pillarsetty N, Bolaender A, Irwin C, Krishnamoorthy GP, Saqcena M, et al. 2016 Sustained ERK inhibition maximizes responses of BrafV600E thyroid cancers to radioiodine. Journal of Clinical Investigation 126 4119-4124. (https://doi.org/10.1172/JCI89067)

Nakamura TM, Morin GB, Chapman KB, Weinrich SL, Andrews WH, Lingner J, Harley CB \& Cech TR 1997 Telomerase catalytic subunit homologs from fission yeast and human. Science 277 955-959. (https://doi.org/10.1126/science.277.5328.955)

Nguyen TT, Scimeca JC, Filloux C, Peraldi P, Carpentier JL \& Van Obberghen E 1993 Co-regulation of the mitogen-activated protein kinase, extracellular signal-regulated kinase 1 , and the $90-\mathrm{kDa}$ ribosomal S6 kinase in PC12 cells. Distinct effects of the neurotrophic factor, nerve growth factor, and the mitogenic factor, 
epidermal growth factor. Journal of Biological Chemistry 268 9803-9810.

Nissan MH, Pratilas CA, Jones AM, Ramirez R, Won H, Liu C, Tiwari S, Kong L, Hanrahan AJ, Yao Z, et al. 2014 Loss of NF1 in cutaneous melanoma is associated with RAS activation and MEK dependence. Cancer Research 74 2340-2350. (https://doi.org/10.1158/0008-5472. CAN-13-2625)

Ohta M, Seto M, Ijichi H, Miyabayashi K, Kudo Y, Mohri D, Asaoka Y, Tada M, Tanaka Y, Ikenoue T, et al. 2009 Decreased expression of the RAS-GTPase activating protein RASAL1 is associated with colorectal tumor progression. Gastroenterology 136 206-216. (https://doi. org/10.1053/j.gastro.2008.09.063)

Okudela K, Yazawa T, Woo T, Sakaeda M, Ishii J, Mitsui H, Shimoyamada H, Sato H, Tajiri M, Ogawa N, et al. 2009 Downregulation of DUSP6 expression in lung cancer: its mechanism and potential role in carcinogenesis. American Journal of Pathology 175 867-881. (https://doi.org/10.2353/ajpath.2009.080489)

Ory S, Zhou M, Conrads TP, Veenstra TD \& Morrison DK 2003 Protein phosphatase $2 \mathrm{~A}$ positively regulates Ras signaling by dephosphorylating KSR1 and Raf-1 on critical 14-3-3 binding sites. Current Biology 13 1356-1364. (https://doi.org/10.1016/S09609822(03)00535-9)

Ozaki K, Kadomoto R, Asato K, Tanimura S, Itoh N \& Kohno M 2001 ERK pathway positively regulates the expression of Sprouty genes. Biochemical and Biophysical Research Communications 285 1084-1088. (https://doi.org/10.1006/bbrc.2001.5295)

Pallier K, Houllier AM, Le Corre D, Cazes A, Laurent-Puig P \& Blons H 2009 No somatic genetic change in the paxillin gene in nonsmallcell lung cancer. Molecular Carcinogenesis 48 581-585. (https://doi. org/10.1002/mc.20538)

Pan CW, Jin X, Zhao Y, Pan Y, Yang J, Karnes RJ, Zhang J, Wang L \& Huang H 2017 AKT-phosphorylated FOXO1 suppresses ERK activation and chemoresistance by disrupting IQGAP1-MAPK interaction. EMBO Journal 36 995-1010. (https://doi.org/10.15252/ embj.201695534)

Park ER, Pullikuth AK, Bailey EM, Mercante DE \& Catling AD 2009 Differential requirement for MEK Partner 1 in DU145 prostate cancer cell migration. Cell Communication and Signaling 7 26. (https://doi. org/10.1186/1478-811X-7-26)

Parsons DW, Jones S, Zhang X, Lin JC, Leary RJ, Angenendt P, Mankoo P, Carter H, Siu IM, Gallia GL, et al. 2008 An integrated genomic analysis of human glioblastoma multiforme. Science $\mathbf{3 2 1}$ 1807-1812. (https://doi.org/10.1126/science.1164382)

Pearce LR, Atanassova N, Banton MC, Bottomley B, Van Der Klaauw AA Revelli JP, Hendricks A, Keogh JM, Henning E, Doree D, et al. 2013 KSR2 mutations are associated with obesity, insulin resistance, and impaired cellular fuel oxidation. Cell 155 765-777. (https://doi. org/10.1016/j.cell.2013.09.058)

Pham N, Cheglakov I, Koch CA, De Hoog CL, Moran MF \& Rotin D 2000 The guanine nucleotide exchange factor CNrasGEF activates ras in response to cAMP and cGMP. Current Biology 10 555-558. (https:// doi.org/10.1016/S0960-9822(00)00473-5)

Porfiri E \& Mccormick F 1996 Regulation of epidermal growth factor receptor signaling by phosphorylation of the ras exchange factor hSOS1. Journal of Biological Chemistry 271 5871-5877. (https://doi. org/10.1074/jbc.271.10.5871)

Poulikakos PI, Zhang C, Bollag G, Shokat KM \& Rosen N 2010 RAF inhibitors transactivate RAF dimers and ERK signalling in cells with wild-type BRAF. Nature 464 427-430. (https://doi.org/10.1038/ nature08902)

Prahallad A, Sun C, Huang S, Di Nicolantonio F, Salazar R, Zecchin D, Beijersbergen RL, Bardelli A \& Bernards R 2012 Unresponsiveness of colon cancer to BRAF(V600E) inhibition through feedback activation of EGFR. Nature 483 100-103. (https://doi.org/10.1038/nature10868)

Pratilas CA, Taylor BS, Ye Q, Viale A, Sander C, Solit DB \& Rosen N 2009 (V600E)BRAF is associated with disabled feedback inhibition of RAF-
MEK signaling and elevated transcriptional output of the pathway. PNAS 106 4519-4524. (https://doi.org/10.1073/pnas.0900780106)

Preger E, Ziv I, Shabtay A, Sher I, Tsang M, Dawid IB, Altuvia Y \& Ron D 2004 Alternative splicing generates an isoform of the human Sef gene with altered subcellular localization and specificity. PNAS 101 1229-1234. (https://doi.org/10.1073/pnas.0307952100)

Prior IA \& Hancock JF 2012 Ras trafficking, localization and compartmentalized signalling. Seminars in Cell and Developmental Biology 23 145-153. (https://doi.org/10.1016/j.semcdb.2011.09.002)

Prior IA, Lewis PD \& Mattos C 2012 A comprehensive survey of Ras mutations in cancer. Cancer Research 72 2457-2467. (https://doi. org/10.1158/0008-5472.CAN-11-2612)

Pritchard CA, Bolin L, Slattery R, Murray R \& Mcmahon M 1996 Postnatal lethality and neurological and gastrointestinal defects in mice with targeted disruption of the A-Raf protein kinase gene. Current Biology 6 614-617. (https://doi.org/10.1016/S0960-9822(02)00548-1)

Pullikuth A, Mckinnon E, Schaeffer HJ \& Catling AD 2005 The MEK1 scaffolding protein MP1 regulates cell spreading by integrating PAK1 and Rho signals. Molecular and Cellular Biology 25 5119-5133. (https://doi.org/10.1128/MCB.25.12.5119-5133.2005)

Pylayeva-Gupta Y, Grabocka E \& Bar-Sagi D 2011 RAS oncogenes: weaving a tumorigenic web. Nature Reviews: Cancer 11 761-774. (https://doi.org/10.1038/nrc3106)

Raghuwanshi SK, Nasser MW, Chen X, Strieter RM \& Richardson RM 2008 Depletion of beta-arrestin-2 promotes tumor growth and angiogenesis in a murine model of lung cancer. Journal of Immunology 180 5699-5706. (https://doi.org/10.4049/ jimmunol.180.8.5699)

Rajagopal S, Rajagopal K \& Lefkowitz RJ 2010 Teaching old receptors new tricks: biasing seven-transmembrane receptors. Nature Reviews: Drug Discovery 9 373-386. (https://doi.org/10.1038/nrd3024)

Ramesh S, Qi XJ, Wildey GM, Robinson J, Molkentin J, Letterio J \& Howe PH 2008 TGF beta-mediated BIM expression and apoptosis are regulated through SMAD3-dependent expression of the MAPK phosphatase MKP2. EMBO Reports 9 990-997. (https://doi. org/10.1038/embor.2008.158)

Ratner N \& Miller SJ 2015 A RASopathy gene commonly mutated in cancer: the neurofibromatosis type 1 tumour suppressor. Nature Reviews: Cancer 15 290-301. (https://doi.org/10.1038/nrc3911)

Ray LB \& Sturgill TW 1988 Insulin-stimulated microtubule-associated protein kinase is phosphorylated on tyrosine and threonine in vivo. PNAS 85 3753-3757. (https://doi.org/10.1073/pnas.85.11.3753)

Ren JG, Li Z \& Sacks DB 2007 IQGAP1 modulates activation of B-Raf. PNAS 104 10465-10469. (https://doi.org/10.1073/ pnas.0611308104)

Renganathan H, Vaidyanathan H, Knapinska A \& Ramos JW 2005 Phosphorylation of PEA-15 switches its binding specificity from ERK/ MAPK to FADD. Biochemical Journal 390 729-735. (https://doi. org/10.1042/BJ20050378)

Reuther GW, Lambert QT, Rebhun JF, Caligiuri MA, Quilliam LA \& Der CJ 2002 RasGRP4 is a novel Ras activator isolated from acute myeloid leukemia. Journal of Biological Chemistry 277 30508-30514. (https://doi.org/10.1074/jbc.M111330200)

Riesco-Eizaguirre G \& Santisteban P 2016 ENDOCRINE TUMOURS: Advances in the molecular pathogenesis of thyroid cancer: lessons from the cancer genome. European Journal of Endocrinology 175 R203-R217. (https://doi.org/10.1530/EJE-16-0202)

Rojas JM \& Santos E 2006 Ras-Gefs and Ras Gaps. In RAS Family GTPases. Proteins and Cell Regulation. Ed. C Der, vol 4. Dordrecht, Netherlands: Springer. (https://doi.org/10.1007/1-4020-4708-8_2)

Roskoski R, Jr 2012 MEK1/2 dual-specificity protein kinases: structure and regulation. Biochemical and Biophysical Research Communications 417 5-10. (https://doi.org/10.1016/j.bbrc.2011.11.145)

Roy M, Li Z \& Sacks DB 2004 IQGAP1 binds ERK2 and modulates its activity. Journal of Biological Chemistry 279 17329-17337. (https:// doi.org/10.1074/jbc.M308405200) https://erc.bioscientifica.com

https://doi.org/10.1530/ERC-19-0098 (c) 2019 Society for Endocrinology Published by Bioscientifica Ltd. Printed in Great Britain 
Roy M, Li Z \& Sacks DB 2005 IQGAP1 is a scaffold for mitogen-activated protein kinase signaling. Molecular and Cellular Biology 25 7940-7952. (https://doi.org/10.1128/MCB.25.18.7940-7952.2005)

Rushworth LK, Kidger AM, Delavaine L, Stewart G, Van Schelven S, Davidson J, Bryant CJ, Caddye E, East P, Caunt CJ, et al. 2014 Dualspecificity phosphatase 5 regulates nuclear ERK activity and suppresses skin cancer by inhibiting mutant Harvey-Ras (HRasQ61L)driven SerpinB2 expression. PNAS 111 18267-18272. (https://doi. org/10.1073/pnas.1420159112)

Sachdev S, Bu Y \& Gelman IH 2009 Paxillin-Y118 phosphorylation contributes to the control of Src-induced anchorage-independent growth by FAK and adhesion. BMC Cancer 9 12. (https://doi. org/10.1186/1471-2407-9-12)

Salgia R, Li JL, Ewaniuk DS, Wang YB, Sattler M, Chen WC, Richards W, Pisick E, Shapiro GI, Rollins BJ, et al. 1999 Expression of the focal adhesion protein paxillin in lung cancer and its relation to cell motility. Oncogene 18 67-77. (https://doi.org/10.1038/sj. onc. 1202273 )

Sancak Y, Bar-Peled L, Zoncu R, Markhard AL, Nada S \& Sabatini DM 2010 Ragulator-Rag complex targets mTORC1 to the lysosomal surface and is necessary for its activation by amino acids. Cell $\mathbf{1 4 1}$ 290-303. (https://doi.org/10.1016/j.cell.2010.02.024)

Sangha N, Wu R, Kuick R, Powers S, Mu D, Fiander D, Yuen K, Katabuchi H, Tashiro H, Fearon ER, et al. 2008 Neurofibromin 1 (NF1) defects are common in human ovarian serous carcinomas and co-occur with TP53 mutations. Neoplasia 10 1362-1372. (https://doi. org/10.1593/neo.08784)

Saraste M, Sibbald PR \& Wittinghofer A 1990 The P-loop - a common motif in ATP- and GTP-binding proteins. Trends in Biochemical Sciences 15 430-434. (https://doi.org/10.1016/0968-0004(90)90281-F)

Sasaki A, Taketomi T, Wakioka T, Kato R \& Yoshimura A 2001 Identification of a dominant negative mutant of Sprouty that potentiates fibroblast growth factor - but not epidermal growth factor-induced ERK activation. Journal of Biological Chemistry 276 36804-36808. (https://doi.org/10.1074/jbc.C100386200)

Sastre-Perona A, Riesco-Eizaguirre G, Zaballos MA \& Santisteban P 2016 Beta-catenin signaling is required for RAS-driven thyroid cancer through PI3K activation. Oncotarget 7 49435-49449. (https://doi. org/10.18632/oncotarget.10356)

Schaeffer HJ, Catling AD, Eblen ST, Collier LS, Krauss A \& Weber MJ 1998 MP1: a MEK binding partner that enhances enzymatic activation of the MAP kinase cascade. Science 281 1668-1671. (https://doi.org/10.1126/science.281.5383.1668)

Scheffzek K, Ahmadian MR, Kabsch W, Wiesmuller L, Lautwein A, Schmitz F \& Wittinghofer A 1997 The Ras-RasGAP complex: structural basis for GTPase activation and its loss in oncogenic Ras mutants. Science 277 333-338. (https://doi.org/10.1126/ science.277.5324.333)

Schiefermeier N, Scheffler JM, De Araujo ME, Stasyk T, Yordanov T, Ebner HL, Offterdinger M, Munck S, Hess MW, Wickstrom SA, et al. 2014 The late endosomal p14-MP1 (LAMTOR2/3) complex regulates focal adhesion dynamics during cell migration. Journal of Cell Biology 205 525-540. (https://doi.org/10.1083/jcb.201310043)

Schmidt VA, Chiariello CS, Capilla E, Miller F \& Bahou WF 2008 Development of hepatocellular carcinoma in Iqgap2-deficient mice is IQGAP1 dependent. Molecular and Cellular Biology 28 1489-1502. (https://doi.org/10.1128/MCB.01090-07)

Sen A, De Castro I, Defranco DB, Deng FM, Melamed J, Kapur P, Raj GV, Rossi R \& Hammes SR 2012 Paxillin mediates extranuclear and intranuclear signaling in prostate cancer proliferation. Journal of Clinical Investigation 122 2469-2481. (https://doi.org/10.1172/ JCI62044)

Shin SH, Park SY \& Kang GH 2013 Down-regulation of dual-specificity phosphatase 5 in gastric cancer by promoter CpG island hypermethylation and its potential role in carcinogenesis. American
Journal of Pathology 182 1275-1285. (https://doi.org/10.1016/j. ajpath.2013.01.004)

Shojaee S, Caeser R, Buchner M, Park E, Swaminathan S, Hurtz C, Geng H, Chan LN, Klemm L, Hofmann WK, et al. 2015 Erk negative feedback control enables pre-B cell transformation and represents a therapeutic target in acute lymphoblastic leukemia. Cancer Cell $\mathbf{2 8}$ 114-128. (https://doi.org/10.1016/j.ccell.2015.05.008)

Short SM, Yoder BJ, Tarr SM, Prescott NL, Laniauskas S, Coleman KA, Downs-Kelly E, Pettay JD, Choueiri TK, Crowe JP, et al. 2007 The expression of the cytoskeletal focal adhesion protein paxillin in breast cancer correlates with HER2 overexpression and may help predict response to chemotherapy: a retrospective immunohistochemical study. Breast Journal 13 130-139. (https://doi. org/10.1111/j.1524-4741.2007.00389.x)

Slack DN, Seternes OM, Gabrielsen M \& Keyse SM 2001 Distinct binding determinants for ERK2/p38alpha and JNK map kinases mediate catalytic activation and substrate selectivity of map kinase phosphatase-1. Journal of Biological Chemistry 276 16491-16500. (https://doi.org/10.1074/jbc.M010966200)

Smallridge RC, Marlow LA \& Copland JA 2009 Anaplastic thyroid cancer: molecular pathogenesis and emerging therapies. EndocrineRelated Cancer 16 17-44. (https://doi.org/10.1677/ERC-08-0154)

Spoerner M, Herrmann C, Vetter IR, Kalbitzer HR \& Wittinghofer A 2001 Dynamic properties of the Ras switch I region and its importance for binding to effectors. PNAS 98 4944-4949. (https:// doi.org/10.1073/pnas.081441398)

Stebbing J, Zhang H, Xu Y, Lit LC, Green AR, Grothey A, Lombardo Y, Periyasamy M, Blighe K, Zhang W, et al. 2015 KSR1 regulates BRCA1 degradation and inhibits breast cancer growth. Oncogene 34 2103-2114. (https://doi.org/10.1038/onc.2014.129)

Sun WY, Hu SS, Wu JJ, Huang Q, Ma Y, Wang QT, Chen JY \& Wei W 2016 Down-regulation of beta-arrestin2 promotes tumour invasion and indicates poor prognosis of hepatocellular carcinoma. Scientific Reports 6 35609. (https://doi.org/10.1038/srep35609)

Swanson KD, Winter JM, Reis M, Bentires-Alj M, Greulich H, Grewal R, Hruban RH, Yeo CJ, Yassin Y, Iartchouk O, et al. 2008 SOS1 mutations are rare in human malignancies: implications for Noonan syndrome patients. Genes, Chromosomes and Cancer 47 253-259. (https://doi.org/10.1002/gcc.20527)

Takemoto H, Doki Y, Shiozaki H, Imamura H, Utsunomiya T, Miyata $H$, Yano M, Inoue M, Fujiwara Y \& Monden M 2001 Localization of IQGAP1 is inversely correlated with intercellular adhesion mediated by E-cadherin in gastric cancers. International Journal of Cancer 91 783-788. (https://doi.org/10.1002/10970215(200002)9999:9999<::AID-IJC1121>3.0.CO;2-Z)

Tanoue T, Moriguchi T \& Nishida E 1999 Molecular cloning and characterization of a novel dual specificity phosphatase, MKP-5. Journal of Biological Chemistry 274 19949-19956. (https://doi. org/10.1074/jbc.274.28.19949)

Tanoue T, Adachi M, Moriguchi T \& Nishida E 2000 A conserved docking motif in MAP kinases common to substrates, activators and regulators. Nature Cell Biology 2 110-116. (https://doi. org/10.1038/35000065)

Tartaglia M, Pennacchio LA, Zhao C, Yadav KK, Fodale V, Sarkozy A, Pandit B, Oishi K, Martinelli S, Schackwitz W, et al. 2007 Gain-offunction SOS1 mutations cause a distinctive form of Noonan syndrome. Nature Genetics 39 75-79. (https://doi.org/10.1038/ ng1939)

Teis D, Wunderlich W \& Huber LA 2002 Localization of the MP1-MAPK scaffold complex to endosomes is mediated by p14 and required for signal transduction. Developmental Cell 3 803-814. (https://doi. org/10.1016/S1534-5807(02)00364-7)

Therrien M, Chang HC, Solomon NM, Karim FD, Wassarman DA \& Rubin GM 1995 KSR, a novel protein kinase required for RAS signal transduction. Cell 83 879-888.
(C) 2019 Society for Endocrinology Published by Bioscientifica Ltd. Printed in Great Britain 
Todaro M, Zerilli M, Ricci-Vitiani L, Bini M, Perez Alea M, Maria Florena A, Miceli L, Condorelli G, Bonventre S, Di Gesu G, et al. 2006 Autocrine production of interleukin- 4 and interleukin-10 is required for survival and growth of thyroid cancer cells. Cancer Research 66 1491-1499. (https://doi.org/10.1158/0008-5472.CAN-052514)

Torii S, Kusakabe M, Yamamoto T, Maekawa M \& Nishida E 2004 Sef is a spatial regulator for Ras/MAP kinase signaling. Developmental Cell $\mathbf{7}$ 33-44. (https://doi.org/10.1016/j.devcel.2004.05.019)

Trahey M \& Mccormick F 1987 A cytoplasmic protein stimulates normal N-ras p21 GTPase, but does not affect oncogenic mutants. Science 238 542-545. (https://doi.org/10.1126/science.2821624)

Traverse S, Gomez N, Paterson H, Marshall C \& Cohen P 1992 Sustained activation of the mitogen-activated protein (MAP) kinase cascade may be required for differentiation of PC12 cells. Comparison of the effects of nerve growth factor and epidermal growth factor. Biochemical Journal 288 351-355.

Trencia A, Perfetti A, Cassese A, Vigliotta G, Miele C, Oriente F, Santopietro S, Giacco F, Condorelli G, Formisano P, et al. 2003 Protein kinase B/Akt binds and phosphorylates PED/PEA-15, stabilizing its antiapoptotic action. Molecular and Cellular Biology 23 4511-4521.

Tsang M, Friesel R, Kudoh T \& Dawid IB 2002 Identification of Sef, a novel modulator of FGF signalling. Nature Cell Biology 4 165-169. (https://doi.org/10.1038/ncb749)

Ueki K, Matsuda S, Tobe K, Gotoh Y, Tamemoto H, Yachi M, Akanuma Y, Yazaki Y, Nishida E \& Kadowaki T 1994 Feedback regulation of mitogen-activated protein kinase kinase kinase activity of c-Raf- 1 by insulin and phorbol ester stimulation. Journal of Biological Chemistry 269 15756-15761.

Untch BR, Dos Anjos V, Garcia-Rendueles MER, Knauf JA, Krishnamoorthy GP, Saqcena M, Bhanot UK, Socci ND, Ho AL, Ghossein R, et al. 2018 Tipifarnib inhibits HRAS-driven dedifferentiated thyroid cancers. Cancer Research 78 4642-4657. (https://doi.org/10.1158/0008-5472.CAN-17-1925)

Vaidyanathan H \& Ramos JW 2003 RSK2 activity is regulated by its interaction with PEA-15. Journal of Biological Chemistry 278 32367-32372. (https://doi.org/10.1074/jbc.M303988200)

Vetter IR \& Wittinghofer A 2001 The guanine nucleotide-binding switch in three dimensions. Science 294 1299-1304. (https://doi. org/10.1126/science.1062023)

Vigil D, Cherfils J, Rossman KL \& Der CJ 2010 Ras superfamily GEFs and GAPs: validated and tractable targets for cancer therapy? Nature Reviews: Cancer 10 842-857. (https://doi.org/10.1038/nrc2960)

Volante M, Collini P, Nikiforov YE, Sakamoto A, Kakudo K, Katoh R, Lloyd RV, Livolsi VA, Papotti M, Sobrinho-Simoes M, et al. 2007 Poorly differentiated thyroid carcinoma: the Turin proposal for the use of uniform diagnostic criteria and an algorithmic diagnostic approach. American Journal of Surgical Pathology 31 1256-1264. (https://doi.org/10.1097/PAS.0b013e3180309e6a)

Vomastek T, Schaeffer HJ, Tarcsafalvi A, Smolkin ME, Bissonette EA \& Weber MJ 2004 Modular construction of a signaling scaffold: MORG1 interacts with components of the ERK cascade and links ERK signaling to specific agonists. PNAS 101 6981-6986. (https:// doi.org/10.1073/pnas.0305894101)

Wang XX, Li XZ, Zhai LQ, Liu ZR, Chen XJ \& Pei Y 2013 Overexpression of IQGAP1 in human pancreatic cancer. Hepatobiliary and Pancreatic Diseases International 12 540-545. (https://doi. org/10.1016/S1499-3872(13)60085-5)

Wartmann M, Hofer P, Turowski P, Saltiel AR \& Hynes NE 1997 Negative modulation of membrane localization of the Raf-1 protein kinase by hyperphosphorylation. Journal of Biological Chemistry 272 3915-3923. (https://doi.org/10.1074/jbc.272.7.3915)

Watanabe Y, Yamasaki F, Kajiwara Y, Saito T, Nishimoto T, Bartholomeusz C, Ueno NT, Sugiyama K \& Kurisu K 2010 Expression of phosphoprotein enriched in astrocytes $15 \mathrm{kDa}$ (PEA-15) in astrocytic tumors: a novel approach of correlating malignancy grade and prognosis. Journal of Neuro-Oncology 100 449-457. (https://doi. org/10.1007/s11060-010-0201-1)

Watanabe T, Wang S \& Kaibuchi K 2015 IQGAPs as key regulators of actin-cytoskeleton dynamics. Cell Structure and Function 40 69-77. (https://doi.org/10.1247/csf.15003)

Watanabe-Okochi N, Oki T, Komeno Y, Kato N, Yuji K, Ono R, Harada Y, Harada H, Hayashi Y, Nakajima H, et al. 2009 Possible involvement of RasGRP4 in leukemogenesis. International Journal of Hematology $\mathbf{8 9}$ 470-481. (https://doi.org/10.1007/s12185-009-0299-0)

Wennerberg K, Rossman KL \& Der CJ 2005 The Ras superfamily at a glance. Journal of Cell Science 118 843-846. (https://doi.org/10.1242/ jcs.01660)

Westerman BA, Braat AK, Taub N, Potman M, Vissers JH, Blom M, Verhoeven E, Stoop H, Gillis A, Velds A, et al. 2011 A genome-wide RNAi screen in mouse embryonic stem cells identifies Mp1 as a key mediator of differentiation. Journal of Experimental Medicine 208 2675-2689. (https://doi.org/10.1084/jem.20102037)

Wojnowski L, Zimmer AM, Beck TW, Hahn H, Bernal R, Rapp UR \& Zimmer A 1997 Endothelial apoptosis in Braf-deficient mice. Nature Genetics 16 293-297. (https://doi.org/10.1038/ng0797-293)

Wong ES, Fong CW, Lim J, Yusoff P, Low BC, Langdon WY \& Guy GR 2002 Sprouty2 attenuates epidermal growth factor receptor ubiquitylation and endocytosis, and consequently enhances Ras/ERK signalling. EMBO Journal 21 4796-4808. (https://doi.org/10.1093/emboj/cdf493)

Wu Z, Jiao P, Huang X, Feng B, Feng Y, Yang S, Hwang P, Du J, Nie Y, Xiao G, et al. 2010 MAPK phosphatase-3 promotes hepatic gluconeogenesis through dephosphorylation of forkhead box O1 in mice. Journal of Clinical Investigation 120 3901-3911. (https://doi. org/10.1172/JCI43250)

Wu K, Liu J, Tseng SF, Gore C, Ning Z, Sharifi N, Fazli L, Gleave M, Kapur P, Xiao G, et al. 2014 The role of DAB2IP in androgen receptor activation during prostate cancer progression. Oncogene $\mathbf{3 3}$ 1954-1963. (https://doi.org/10.1038/onc.2013.143)

Wunderlich W, Fialka I, Teis D, Alpi A, Pfeifer A, Parton RG, Lottspeich F \& Huber LA 2001 A novel 14-kilodalton protein interacts with the mitogen-activated protein kinase scaffold mp1 on a late endosomal/ lysosomal compartment. Journal of Cell Biology 152 765-776. (https://doi.org/10.1083/jcb.152.4.765)

Xing M 2007 Gene methylation in thyroid tumorigenesis. Endocrinology 148 948-953. (https://doi.org/10.1210/en.2006-0927)

Xing HR, Cordon-Cardo C, Deng X, Tong W, Campodonico L, Fuks Z \& Kolesnick R 2003 Pharmacologic inactivation of kinase suppressor of ras-1 abrogates Ras-mediated pancreatic cancer. Nature Medicine $\mathbf{9}$ 1266-1268. (https://doi.org/10.1038/nm927)

Xu S, Furukawa T, Kanai N, Sunamura M \& Horii A 2005 Abrogation of DUSP6 by hypermethylation in human pancreatic cancer. Journal of Human Genetics 50 159-167. (https://doi.org/10.1007/s10038-0050235-y)

Yang FC, Chen S, Clegg T, Li X, Morgan T, Estwick SA, Yuan J, Khalaf W, Burgin S, Travers J, et al. 2006 Nf1+/- mast cells induce neurofibroma like phenotypes through secreted TGF-beta signaling. Human Molecular Genetics 15 2421-2437. (https://doi.org/10.1093/hmg/ dd1165)

Yang D, Kedei N, Li L, Tao J, Velasquez JF, Michalowski AM, Toth BI, Marincsak R, Varga A, Biro T, et al. 2010a RasGRP3 contributes to formation and maintenance of the prostate cancer phenotype. Cancer Research 70 7905-7917. (https://doi.org/10.1158/0008-5472. CAN-09-4729)

Yang HJ, Chen JZ, Zhang WL \& Ding YQ 2010 $b$ Focal adhesion plaque associated cytoskeletons are involved in the invasion and metastasis of human colorectal carcinoma. Cancer Investigation 28 127-134. (https://doi.org/10.3109/07357900903147184)

Yang D, Tao J, Li L, Kedei N, Toth ZE, Czap A, Velasquez JF, Mihova D, Michalowski AM, Yuspa SH, et al. 2011 RasGRP3, a Ras activator, contributes to signaling and the tumorigenic phenotype in human https://erc.bioscientifica.com

https://doi.org/10.1530/ERC-19-0098 (c) 2019 Society for Endocrinology Published by Bioscientifica Ltd. Printed in Great Britain 
melanoma. Oncogene 30 4590-4600. (https://doi.org/10.1038/ onc.2011.166)

Yang Y, Zhao W, Xu QW, Wang XS, Zhang Y \& Zhang J 2014 IQGAP3 promotes EGFR-ERK signaling and the growth and metastasis of lung cancer cells. PLoS ONE 9 e97578. (https://doi.org/10.1371/journal. pone.0097578)

Yano M, Toyooka S, Tsukuda K, Dote H, Ouchida M, Hanabata T, Aoe M, Date H, Gazdar AF \& Shimizu N 2005 Aberrant promoter methylation of human DAB2 interactive protein (hDAB2IP) gene in lung cancers. International Journal of Cancer 113 59-66. (https://doi. org/10.1002/ijc.20531)

Yoon S \& Seger R 2006 The extracellular signal-regulated kinase: multiple substrates regulate diverse cellular functions. Growth Factors 24 21-44. (https://doi.org/10.1080/02699050500284218)

Zaballos MA \& Santisteban P 2013 FOXO1 controls thyroid cell proliferation in response to TSH and IGF-I and is involved in thyroid tumorigenesis. Molecular Endocrinology 27 50-62. (https://doi. org/10.1210/me.2012-1032)

Zaballos MA \& Santisteban P 2017 Key signaling pathways in thyroid cancer. Journal of Endocrinology 235 R43-R61. (https://doi. org/10.1530/JOE-17-0266)

Zakrzewska M, Haugsten EM, Nadratowska-Wesolowska B, Oppelt A, Hausott B, Jin Y, Otlewski J, Wesche J \& Wiedlocha A 2013 ERKmediated phosphorylation of fibroblast growth factor receptor 1 on Ser777 inhibits signaling. Science Signaling 6 ra11. (https://doi. org/10.1126/scisignal.2003087)
Zanca C, Garofalo M, Quintavalle C, Romano G, Acunzo M, Ragno P, Montuori N, Incoronato M, Tornillo L, Baumhoer D, et al. 2008 PED is overexpressed and mediates TRAIL resistance in human non-small cell lung cancer. Journal of Cellular and Molecular Medicine $\mathbf{1 2}$ 2416-2426. (https://doi.org/10.1111/j.1582-4934.2008.00283.x)

Zhang Q, Muller M, Chen CH, Zeng L, Farooq A \& Zhou MM 2005 New insights into the catalytic activation of the MAPK phosphatase PAC-1 induced by its substrate MAPK ERK2 binding. Journal of Molecular Biology 354 777-788. (https://doi.org/10.1016/j. jmb.2005.10.006)

Zhang X, Li N, Li X, Zhao W, Qiao Y, Liang L \& Ding Y 2012 Low expression of DAB2IP contributes to malignant development and poor prognosis in hepatocellular carcinoma. Journal of Gastroenterology and Hepatology 27 1117-1125. (https://doi. org/10.1111/j.1440-1746.2011.07049.x)

Zhu TN, He HJ, Kole S, D'souza T, Agarwal R, Morin PJ \& Bernier M 2007 Filamin A-mediated down-regulation of the exchange factor Ras-GRF1 correlates with decreased matrix metalloproteinase-9 expression in human melanoma cells. Journal of Biological Chemistry 282 14816-14826. (https://doi.org/10.1074/jbc. M611430200)

Zisman-Rozen S, Fink D, Ben-Izhak O, Fuchs Y, Brodski A, Kraus MH, Bejar J \& Ron D 2007 Downregulation of Sef, an inhibitor of receptor tyrosine kinase signaling, is common to a variety of human carcinomas. Oncogene 26 6093-6098. (https://doi.org/10.1038/sj. onc.1210424)

Received in final form 9 April 2019

Accepted 11 April 2019

Accepted Preprint published online 12 April 2019
C) 2019 Society for Endocrinology Published by Bioscientifica Ltd. Printed in Great Britain 